\author{
UNIVERSIDADE DE BRASILIA \\ INSTITUTO DE GEOCIÊNCIAS \\ CURSO DE ESPECIALIZAÇÃO EM GEOPROCESSAMENTO
}

\title{
USO SÉRIES TEMPORAIS DE ÍNDICES DE VEGETAÇÃO DE IMAGENS MODIS COMO FERRAMENTA DE MONITORAMENTO DE INDICE DE ÁREA FOLIAR EM PLANTIOS DE Eucalyptus NO SUL DA BAHIA
}

\author{
Arthur Vrechi
}

Orientador: Prof. Dr. Edson Eyji Sano

MONOGRAFIA DE CONCLUSÃO DE CURSO DE ESPECIALIZAÇÃO

BRASÍLIA 


\author{
UNIVERSIDADE DE BRASILIA \\ INSTITUTO DE GEOCIÊNCIAS \\ CURSO DE ESPECIALIZAÇÃO EM GEOPROCESSAMENTO
}

\title{
USO SÉRIES TEMPORAIS DE ÍNDICES DE VEGETAÇÃO DE IMAGENS MODIS COMO FERRAMENTA DE MONITORAMENTO DE INDICE DE ÁREA FOLIAR EM PLANTIOS DE Eucalyptus NO SUL DA BAHIA
}

\begin{abstract}
Arthur Vrechi
Orientador: Prof. Dr. Edson Eyji Sano

MONOGRAFIA DE CONCLUSÃO DE CURSO DE ESPECIALIZAÇÃO
\end{abstract}

BRASÍLIA

2011 


\section{RESUMO}

\section{Uso séries temporais de índices de vegetação de imagens MODIS como ferramenta de monitoramento de índice de área foliar em plantios de Eucalyptus no Sul da Bahia}

O entendimento da dinâmica de parâmetros fisiológicos em plantios florestais é importante para compreender as relações entre produtividade, aspectos genéticos e o meio físico, e nisso, o uso do sensoriamento remoto e geoprocessamento têm ganhado destaque nos últimos anos. Este trabalho visou avaliar a aplicação de séries temporais de índice de vegetação, extraídas de imagens do sensor orbital MODIS, como ferramenta de monitoramento de IAF (índice de área foliar) em áreas de plantios florestais, através do estudo de relações entre o IAF e índices de vegetação e o desenvolvimento ou uso de métodos para o processamento das imagens e das séries temporais. Foram utilizadas imagens obtidas entre os anos de 2002 a 2011, com dados de reflectâncias nas bandas do azul, vermelho e infravermelho e os índices de vegetação NDVI (Normalized Difference Vegetation Index) e EVI (Enhanced Vegetation Index). Foram testados três índices de qualidade da informação, visando a eliminação de dados inconsistentes: os dois primeiros gerados pelo produto MODIS e o terceiro utilizando as bandas do vermelho e azul como indicadores. Foi realizada a suavização da série temporal utilizando o filtro de Savitzky-Golay, para reduzir as variações de curta escala temporal, causadas por diferenças em ângulos de visada, resíduos das correções atmosféricas e incertezas de outras naturezas. Foram coletados dados de IAF em campo em noventa áreas, estratificadas por classe de idade e tamanho dos talhões, utilizando o método de fotos hemisféricas. Utilizou-se, ainda, dados existentes de IAF para nove talhões, visando verificar a eficácia do modelo. Os valores de IAF das parcelas de calibração variaram de 1,3 a $5,7 \mathrm{~m}^{2} / \mathrm{m}^{2}$, e foi observado um decréscimo do IAF com o aumento da idade dos plantios. Observou-se que, na região de estudo, os pixels do MODIS que estão inseridos inteiramente em um talhão, podem representar $50,4 \%$ das áreas de plantio de eucalipto da região. O índice de qualidade desenvolvido para esse estudo apresentou melhor eficiência em relação aos disponibilizados pelo MODIS, reduzindo o coeficiente de variação de 15 para 11\% e excluindo 22\% dos valores, em uma média para dez talhões avaliados. Não foi observada uma melhora evidente da estimativa de IAF com o aumento do tamanho dos alvos. Obteve-se melhores resultados para estimar o IAF através do $\mathrm{EVI}$, que apresentou um coeficiente de determinação $\left(R^{2}\right)$ de 0,90 e erro médio quadrático (RMSE) de $0,81 \mathrm{~m}^{2} / \mathrm{m}^{2}$, utilizando-se uma regressão logística. A verificação da eficácia do modelo resultou em uma correlação significativa $\left(R^{2}=0,737\right.$ e $\operatorname{RMSE}=0,67$ $\mathrm{m}^{2} / \mathrm{m}^{2}$ ), com leve tendência para subestimação do IAF. Sugere-se a realização de um monitoramento contínuo de IAF em campo para testar a eficiência do modelo ao longo do tempo. Através do tratamento da série temporal e do banco de dados gerado, foi possível sugerir aplicações práticas para a ferramenta, como por exemplo, a avaliação do tempo de fechamento de dossel dos plantios e estimativa de danos causados por agentes externos, como fogo, pragas e doenças.

Palavras chave: Índice de área foliar, sensoriamento remoto, Eucalyptus, índice de vegetação, MODIS 


\section{ABSTRACT \\ Using MODIS vegetation index time-series as a tool for monitoring leaf area index on Eucalyptus plantations in Bahia South, Brazil}

Understanding the dynamics of physiological parameters on forest plantations is important in order to comprehend relationships among productivity, genetics and environment, and the use of remote sensing and geoprocessing tools for this studies have been increasing in recent years. This study aimed to evaluate the potential of using vegetation index timeseries, generated from MODIS, as a tool for monitoring LAI (leaf area index) on forest plantations, through relationships between LAl and vegetation index and developing methodologies for processing images and time-series. Images from 2002 to 2011 were used, with reflectance data for blue, red and infrared bands and two vegetation indexes: NDVI (Normalized Difference Vegetation Index) e EVI (Enhanced Vegetation Index). Three information quality indexes were tested, in order to eliminate bad data: the first two using quality index generated by MODIS product and the third was proposed in this work. A smoothing of time-series was carried out using Savitzky-Golay filter, for reducing short time scale variations, such as differences on view angle, atmospheric correction and others uncertainties. Ground truth LAI data were collected for ninety stands, stratified by age class and stand size, using hemispherical photography. Existing LAl data for nine stands were used for verifying the model accuracy. LAI values from calibration stands varied from $1.3 \mathrm{~m}^{2} / \mathrm{m}^{2}$ to $5.7 \mathrm{~m}^{2} / \mathrm{m}^{2}$, and were observed a LAI decrease as the plantations age increases. For the study area, were calculated the area of Eucalyptus plantation represented by one or more MODIS pixels, since the pixel were completely contained in a stand, which was $50.4 \%$ from the total plantation areas. The quality index developed on this work showed improved efficiency in relation to MODIS quality indexes, reducing coefficient of variation from $15 \%$ to $11 \%$ and excluding $22 \%$ of bad data, in average for ten evaluated stands. There was no clear improvement on LAl estimation when stands size increases. EVI was better than NDVI o estimate LAl, which showed a coefficient of determination $\left(R^{2}\right)$ of 0.90 and a mean squared error (RMSE) of $0.81 \mathrm{~m}^{2} / \mathrm{m}^{2}$, using a logistic model. The model accuracy resulted in a significant correlation $\left(R^{2}=0.737\right.$ e RMSE $\left.=0.67 \mathrm{~m}^{2} / \mathrm{m}^{2}\right)$ with a slight trend toward underestimation of LAI. A continuous field monitoring on LAI were suggested in order to evaluate the model accuracy over time. Through time-series processing and the database created, was possible to suggest practical applications for the tool, such as canopy closure time for stands, estimations of damage caused by external agents, such as fire, pests and diseases.

Keywords: leaf index area, remote sensing, Eucalyptus, vegetation index, MODIS 


\section{Lista de ilustrações}

Figura 1. Localização da área de estudo (sul do estado da Bahia). 15

Figura 2. Foto de área de plantio de eucalipto e áreas de preservação, formando um mosaico florestal de produção e áreas de conservação.

Figura 3. Média histórica de precipitação e temperatura para dois locais distintos da região a) Porto Seguro-BA, situado mais próximo ao litoral e b) Guaratinga-BA, situado nas áreas mais à oeste.

Figura 4. Localização das áreas de coleta de IAF em campo, para calibração e verificação do modelo em relação às áreas de manejo florestal da empresa (eucalipto e áreas de preservação).

Figura 5. Avaliação de foto hemisférica para obtenção do IAF no software Hemisfer ${ }^{\circledR}$.

Figura 6. Talhão recém colhido, representando classe de IAF igual a zero.

Figura 7. Grade de cenas do produtos MODIS de índice de vegetação com destaque para a cena utilizada (em vermelho). 23

Figura 8. Exemplo da aplicação da metologia de identificação dos pixels de interesse e estratificação em relação ao tamanho do talhão: a) com redução de $100 \mathrm{~m}$ de faixa,

b) $150 \mathrm{~m} \mathrm{e} \mathrm{c)} 250 \mathrm{~m}$. 25

Figura 9. IAF coletado em campo em relação à idade da floresta em anos, mostrando o decréscimo dos valores de IAF com o estabelecimento da floresta. 32

Figura 10. Espacialização das áreas disponíveis para plantio representadas no estudo (cobertas pelo MODIS) em verde, e as áreas não representadas (em cinza).

Figura 11. Exemplo da aplicação dos filtros testados para retirada de valores inconsistentes, sendo a) retirada do IQ do MODIS $=1$, b) retirada do IQ do MODIS = 1 e 3 e c) índice de confiabilidade proposto...

Figura 12. Relação entre IAF medido e NDVI, para os três tratamentos testados....... 40

Figura 13. Relação entre IAF medido e NDVI, para todo o conjunto de dados. ..........40

Figura 14. Relação entre IAF medido e EVI, para os três tratamentos testados..........42

Figura 15. Relação entre IAF medido e EVI, para todo o conjunto de dados.

Figura 16. Relação entre IAF real e o estimado pelo MODIS, para os dados de verificação. 44

Figura 17. Dispersão dos resíduos em função do IAF real medido em campo. 44

Figura 18. Séries temporais de IAF para as áreas de verificação e valores obtidos em campo (pontos em vermelho). A linha tracejada (vermelha) indica o corte e início de um novo ciclo da floresta. 


\section{Lista de tabelas}

Tabela 1. Áreas representadas pelos pixels do MODIS, com estratificação pelo tamanho dos talhões e áreas não representadas............................................... 33

Tabela 2. Resumo da aplicação do filtragem usando o IQ (1) do MODIS. ...................35

Tabela 3. Resumo da aplicação do filtragem usando o IQ (1 e 3) do MODIS................36

Tabela 4. Resumo da aplicação do filtragem usando o índice de confiabilidade

proposto.

Tabela 5. Equações ajustadas para a relação entre IAF e NDVI , coeficiente de determinação $\left(R^{2}\right)$, erro médio quadrático (RMSE) e valor-p para os tratamentos analisados.

Tabela 6. Equações ajustadas para a relação entre IAF e EVI , coeficiente de determinação $\left(R^{2}\right)$, erro médio quadrático (RMSE) e valor-p para os tratamentos analisados.

Tabela 7. Áreas de verificação com coordenadas, idade, IAF real e estimado e datas dos inícios dos ciclos de plantio.

Tabela 8. Estrutura do banco de dados para armazenamento das informações processadas. 


\section{SUMÁRIO}

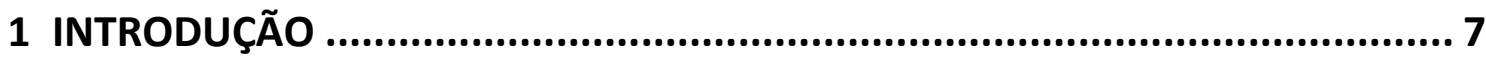

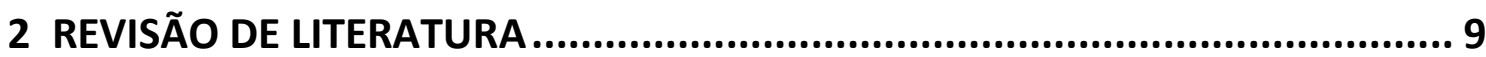

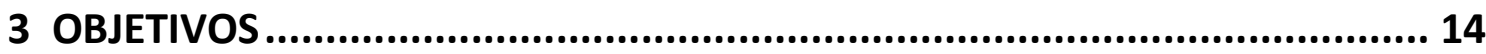

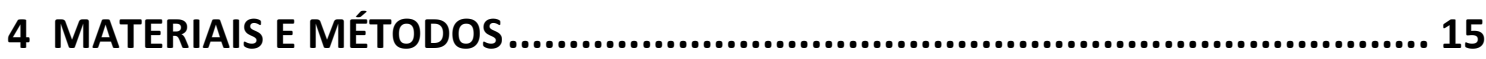

4.1 Área de estudo ....................................................................................................... 15

4.2 Seleção dos talhões ........................................................................................... 17

4.3 Obtenção de dados de IAF em campo …………………........................................20

4.4 Produto do sensor MODIS ...................................................................................... 22

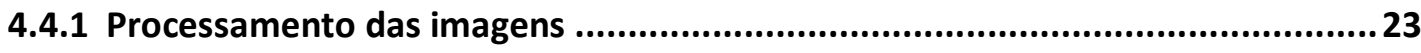

4.4.1.1 Extração dos dados das áreas de interesse ......................................................23

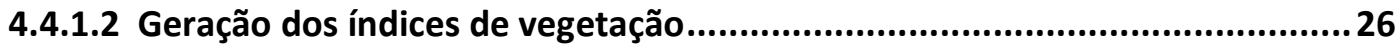

4.4.1.3 Tratamento da série temporal ....................................................................27

4.4.1.4 Estruturação da base de dados ................................................................. 30

4.5 Análise de dados e verificação do modelo ................................................................. 30

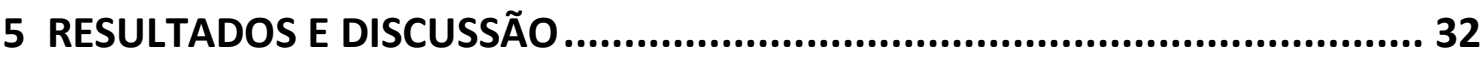

5.1 Dados de IAF obtidos em campo............................................................................. 32

5.2 Extração de dados do MODIS para áreas de interesse ..............................................33

5.3 Tratamento da série temporal .................................................................................... 35

5.4 Relações entre índices de vegetação e IAF .............................................................. 39

5.5 Verificação da eficácia do modelo................................................................................. 43

5.6 Estrutura final da base de dados.............................................................................48

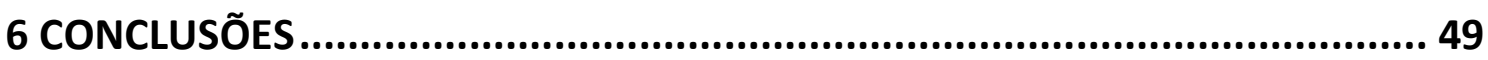




\section{INTRODUÇÃO}

O setor florestal brasileiro ocupa posição de destaque na economia brasileira, contribui com 3,5\% do PIB e gera aproximadamente 3,9 milhões de empregos diretos e indiretos, em todos os segmentos. As florestas plantadas de Eucalyptus e Pinus atingiram em 2010 o valor de 6,5 milhões de hectares, sendo que a área plantada com eucalipto foi de aproximadamente 4,75 milhões, o que representa uma expansão de 5,3\% da área plantada em relação ao ano anterior (ABRAF, 2011).

De acordo com ORTIZ et al. (2006), assim como se verifica atualmente com a agricultura, na área florestal também é possível a adoção de uma abordagem visando o gerenciamento localizado de atividades silviculturais, a Silvicultura de Precisão, que se baseia, segundo VETTORAZZI e FERRAZ (2000), na coleta e na análise de dados de natureza espacial, viabilizando intervenções localizadas na floresta com a exatidão e a precisão adequadas.

Dentro do contexto de Silvicultura de Precisão enquadram-se as ferramentas de sensoriamento remoto que, devido ao grande número de produtos gerados e à facilidade ao seu acesso, assumem grande importância nessa abordagem, pois fornecem subsídios para a identificação e correlação de variáveis que afetam a produtividade florestal e que podem ser analisadas por meio de operações em Sistemas de Informações Geográficas (SIGs).

O índice de área foliar (IAF) é um importante parâmetro fisiológico das florestas e o entendimento de sua variação no espaço e tempo, pode trazer um maior conhecimento sobre a dinâmica de crescimento da floresta e sobre fatores que a influenciam, assim como pode auxiliar no desenvolvimento de modelos que permitem equacionar produtividade, consumo de água e fixação de carbono (STAPE et al, 2004). 
Segundo LANDSBERG (2003), esses modelos processuais, baseados em estudos ecofisiológicos, possibilitam estimar o potencial produtivo de áreas sem mensurações, acessar o crescimento real de florestas, avaliar danos de pragas ou doenças e simular prováveis efeitos de mudanças climáticas no crescimento da floresta.

Vários trabalhos demonstraram a possibilidade do uso de imagens de satélite de diversos sensores para modelagem do IAF, assim como sua utilização em aplicações diversas, (XAVIER \& VETTORAZZI, 2004, PAIVA et al. 2009 e MARSDEN et al., 2010). Porém, é importante considerar que existem fatores locais que influenciam a calibração desses modelos e também é desejável que essa técnica possa ser aplicada na rotina de trabalho dos empreendimentos florestais, tornando-se uma ferramenta de monitoramento e tomada de decisão para a área operacional e auxiliando os trabalhos de pesquisa florestal, visando a busca de plantios mais produtivos aliados a bases sustentáveis.

Dessa forma, este estudo teve como objetivo analisar o potencial das séries temporais de índice de vegetação do sensor orbital MODIS (ModerateResolution Imaging Spectroradiometer), como ferramenta de monitoramento de IAF em plantios de eucalipto no sul da Bahia. 


\section{REVISÃO DE LITERATURA}

A utilização de geotecnologias nas ciências da terra tem crescido rapidamente nas últimas décadas. Isso se deve ao aumento da disponibilidade de produtos de sensoriamento remoto e de softwares de geoprocessamento que, estão cada vez mais acessíveis aos pesquisadores e profissionais da área. Diversos são os estudos e produtos gerados a partir desses trabalhos, com destaque para as áreas ambiental, produtiva (agricultura e florestal) e de planejamento.

$\mathrm{Na}$ área ambiental, podem ser citados trabalhos de detecção de desmatamentos, como os apresentados por ARAGÃO, ARAI e SHIMABUKURO (2009), que utilizaram tratamentos em imagens do sensor MODIS com software gratuito Spring visando, entre outras aplicações, quantificações de áreas desmatadas. CARDOZO et al. (2011), avaliaram o potencial do uso de índices de vegetação e índices de queimada, através de imagens do TM/Landsat-5, visando mapear áreas de queimada no centro-oeste do Brasil, concluindo que o índice de queimada apresentou alta eficiência na determinação da ocorrência e severidade de incêndios.

Estudos com mapeamentos de uso da terra com imagens de satélite são amplamente utilizados para orientar o planejamento e zoneamento agrícola dos estados. SANO et al. (2008) mapearam o uso da terra no bioma Cerrado através de imagens TM/LandSat, abrangendo 9 estados brasileiros, tendo uma exatidão final global de $96,5 \%$.

Na área agrícola, RIZZI \& RUDORFF (2007) trabalharam com estimativa de produtividade de soja no Rio Grande do Sul usando índices de vegetação gerados com imagens do MODIS e observaram que os modelos que utilizaram essas informações obtiveram estimativas detalhadas sobre a variabilidade espacial da produtividade da cultura. Já PONTES, ROCHA e LAMPARELLI (2005) analisaram séries temporais de índices de vegetação obtidas com imagens do Landsat7/ETM+, visando a previsão de safras de cana-de-açúcar, encontrando um bom potencial do uso desses índices para a estimativa das safras. 
Na área de florestas plantadas, várias são as utilizações de produtos de sensoriamento remoto e geoprocessamento, como por exemplo, delimitações de áreas de plantios, inventário de número de árvores plantadas, planejamento de construção de estradas, entre outros. Estudos envolvendo estimativa de parâmetros biofísicos das florestas através de imagens de satélite, como o IAF, biomassa, estrutura de dossel e radiação solar absorvida, também tem sido comuns nos últimos anos.

GIUNTI NETO et al. (2008) utilizaram fotos hemisféricas, também considerada uma técnica de sensoriamento remoto, para estimar o IAF em plantios de Eucalyptus no sul da Bahia. Foi encontrada uma alta correlação entre os valores de IAF estimados com as fotos hemisféricas com os valores encontrados em campo através de amostras destrutivas. Esse trabalho permitiu que se entendesse a dinâmica do IAF ao longo do tempo e suas influências na produtividade florestal. PAIVA et al. (2009), avaliaram a correlação do IAF obtido através de fotos hemisféricas coletadas em campo com índices de vegetação NDVI (Normalized Difference Vegetation Index) e EVI (Enhanced Vegetation Index) do sensor MODIS e TM/Landsat, concluindo que o produto NDVI do sensor MODIS apresentou a melhor correlação com o IAF.

XAVIER et al. (1998) avaliaram o uso de técnicas de sensoriamento remoto, com imagens TM/Landsat, para estimar o IAF em diferentes materiais genéticos de Eucalyptus, no Espírito Santo, Brasil. Foram coletados dados em campo com o analisador de dossel LAI- $2000^{\circledR}$ e comparados com os índices de vegetação SAVI (Soil Adjusted Vegetation Index) e NDVI, sendo que o primeiro apresentou melhores índices de correlação com o IAF. Ainda, nas estimativas do SAVI, não foram encontradas diferenças utilizando diferentes fatores de correção de solo.

Observa-se que os diversos índices de vegetação (NDVI, EVI, SAVI) tem sido altamente empregados em estudos com IAF em plantios de Eucalyptus, e os trabalhos relacionados acima mostram claramente a possibilidade do uso de imagens de diversos satélites (MODIS, TM/Landsat, CBERS, ASTER, etc.) para estimativa de IAF. O tipo de imagem e o índice de vegetação a serem utilizados dependem da diversos 
fatores, como região de estudo, espécie ou material genético plantados, tamanho dos plantios, entre outros, sendo importante avaliar esses aspectos ao iniciar estudos dessa natureza.

As imagens do satélite MODIS tem recebido grande importância nesse tipo de avaliação. JUSTICE et al. (1998), apresentaram como destaque do MODIS a geração de produtos já processados, com relação à correções atmosféricas e geométrica, composições temporais e espaciais, que poupam tempo da comunidade científica, possibilitando focar os esforços na resolução de questões da ciência em vez do processamento de dados. Também, evidenciam como ponto positivo, a sua alta resolução temporal e as conseqüentes possibilidades de avaliações multitemporais. Outro aspecto importante é a facilidade de acesso e gratuidade dessas informações.

Todos os estudos citados apresentaram avaliações pontuais de relações entre o IAF e índices de vegetação. Em estudos pontuais, pode-se selecionar imagens livres de nuvens, facilitando o processo de correções. Para as abordagens com séries temporais de índices de vegetação, é importante a adoção de métodos de filtragens e correção de ruídos, conforme apontado por HUETE et al. (2002), que discutiram os efeitos dos ângulos de visada e contaminação residual de nuvens e aerossóis da atmosfera nas séries temporais dos produtos de índice de vegetação do MODIS.

FREITAS \& SHIMABUKURO (2008) estudaram uma metodologia para tratamento das séries temporais de índice de vegetação obtidas com o MODIS, no período de 2000 a 2006, em áreas do Mato Grosso, Brasil. Como método de correção da série temporal, utilizaram a transformada wavelet para decomposição de sinal e eliminação de ruídos de alta freqüência. Os métodos de correções utilizados mostraram-se aptos a serem aplicados em séries temporais, tendo em vista os resultados obtidos.

FREITAS et al. (2011) estudaram o índice de vegetação EVI2 para toda a América do Sul, obtido através do sensor MODIS, no período de 2000 a 2009, com o objetivo de visualizar os dados de forma instantânea através de ferramentas web. Além da transformada wavelet, utilizaram uma filtragem inicial que exclui 
informações de pixels com valores maiores do que $10 \%$ de reflectância na banda do azul e ângulos de visada maiores do que 30 graus. Essa primeira filtragem visou a redução de efeitos de nuvens e sombra de nuvens e, combinada com a segunda filtragem, possibilitaram a aplicação das séries temporais em análises de padrões de conversão de uso e cobertura do solo e dinâmica de vegetações.

MARSDEN et al. (2010), avaliaram a relação entre séries temporais do índice de vegetação NDVI, obtidos através de imagens do sensor MODIS, e parâmetros biofísicos de florestas de Eucalyptus no estado de São Paulo. Foram utilizados dois passos principais para filtragem de dados em série temporal, no nível de pixel. 0 primeiro consistiu em retirar os valores de NDVI para pixels com ângulo de visada maior do que 40 graus e pixels com indicador de não-confiabilidade, informação essa que faz parte do produto de índice de vegetação do MODIS. Nesse passo, foram eliminados os valores inferiores a $10 \%$ dos precedentes e posteriores. Em um segundo passo, os valores restantes foram ajustados em uma função de suavização (pelo método spline), visando reduzir as variações de curta escala temporal, como variações derivadas de diferentes ângulos de visada e resíduos das correções atmosféricas.

Ainda, MARSDEN et al. (2010), preocuparam-se com a representatividade do pixel em relação aos alvos, utilizando somente áreas suficientemente grandes (para englobar mais de um pixel) e de forma homogênea para avaliação, devido a incertezas da localização do pixel. DUNGAN \& GANAPOL (2003) destacaram o posicionamento geográfico como fonte de incerteza em resultados de trabalhos com - MODIS, sendo importante o entendimento dessas incertezas na construção de modelos. Não foram encontrados em literatura estudos com tamanhos de alvos ideais e necessidade de faixa de bordadura para se ter resultados confiáveis de IAF obtidos através índices de vegetação de imagens do MODIS.

Da revisão de literatura aqui apresentada, conclui-se que a obtenção de IAF para florestas de Eucalyptus, gerados a partir de índices de vegetação de imagens de satélite, requer uma avaliação do tipo de imagem, dos índices de vegetação e dos 
métodos de correção ou filtragem a serem utilizados. Tal avaliação é função das características da área e da espécie estudada. É importante ainda avaliar os limites espaciais referentes às dimensões do pixel e alvo trabalhado. 


\section{OBJETIVOS}

Esse trabalho visou avaliar o potencial do uso de séries temporais de índice de vegetação, extraídas de imagens de satélite do sensor MODIS, como ferramenta de monitoramento de IAF em áreas de plantios florestais. Como objetivos específicos tem-se:

a) Estabelecer métodos para tratamento das imagens e extração das informações para áreas de interesse, visando a obtenção de séries temporais de índices de vegetação consistentes;

b) Desenvolver fluxogramas e modelos computacionais em ambiente SIG e parametrizar um banco de dados para armazenamento e análise das informações, tendo em vista a operacionalização do processo;

c) Estabelecer relações entre os índices de vegetação obtidos com o processamento das imagens e o IAF real obtido nas áreas de reflorestamento em estudo, assim como avaliar a eficácia do modelo através de pontos de verificação. 


\section{MATERIAIS E MÉTODOS}

\section{1 Área de estudo}

O estudo foi realizado nos plantios florestais da empresa Veracel Celulose S.A., no sul do estado da Bahia, Brasil, nas bacias hidrográficas dos rios Pardo e Jequitinhonha, entre as latitudes 1534'S e 16950'S e longitudes 39001'W e 4023'W, com altitude média de $180 \mathrm{~m}$ (Figura 1).
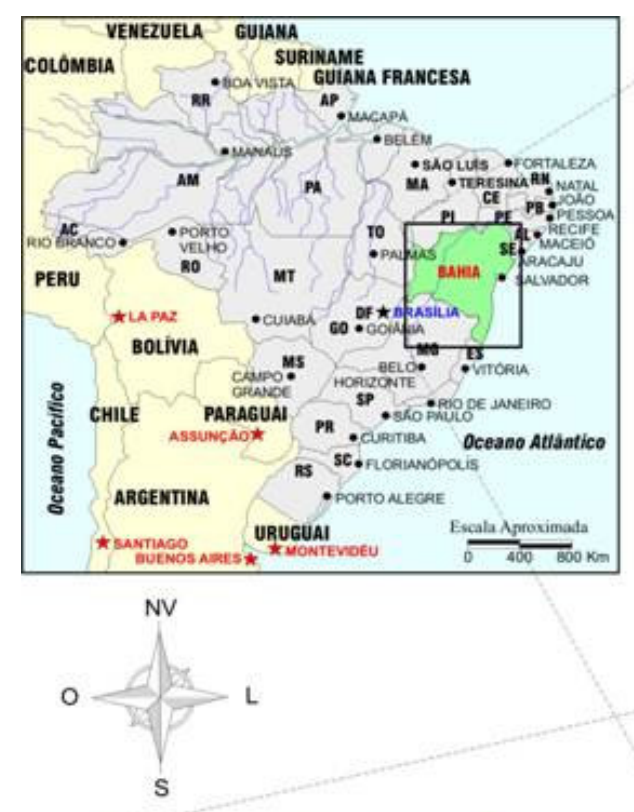

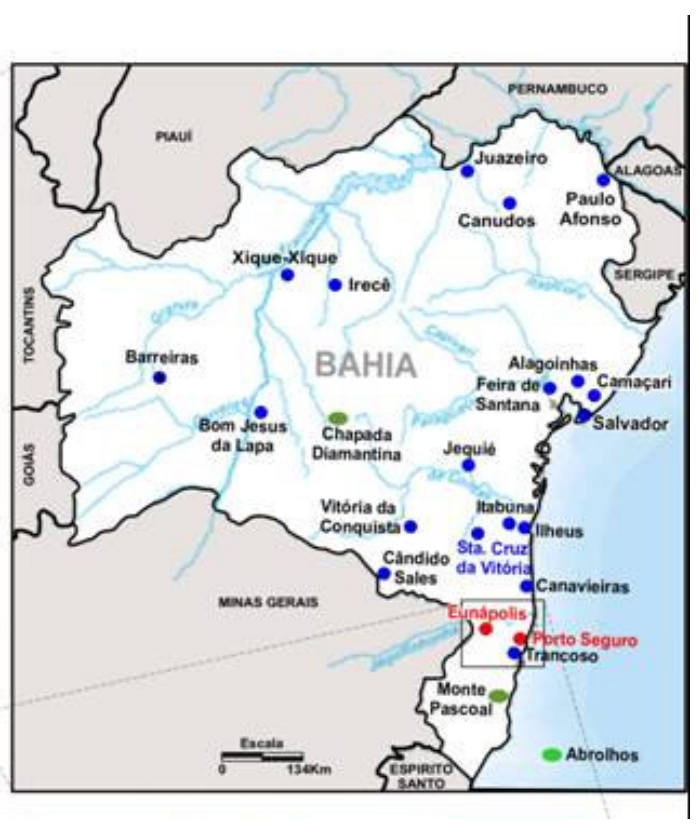

Figura 1. Localização da área de estudo (sul do estado da Bahia).

Nos plantios florestais são utilizados materiais genéticos clonais de Eucalyptus obtidos a partir do cruzamento das espécies Eucalyptus grandis (W. Hill ex Maiden) e Eucalyptus urophylla (S.T. Blake). No cultivo do eucalipto, as áreas de manejo (denominadas talhões) são divididas fisicamente e possuem o mesmo material genético e manejo silvicultural. Em geral, a floresta é colhida entre 5 a 8 anos, sendo que, após a colheita, é realizada a condução da brotação das cepas cortadas ou o plantio de novas mudas. Ambos os casos dão origem a uma nova floresta ou ciclo de produção. 
Os plantios de eucalipto dividem a paisagem com áreas de preservação (áreas de preservação permanente, remanescentes de Mata Atlântica e áreas em regeneração), formando mosaicos de áreas de produção e áreas preservadas (Figura 2).

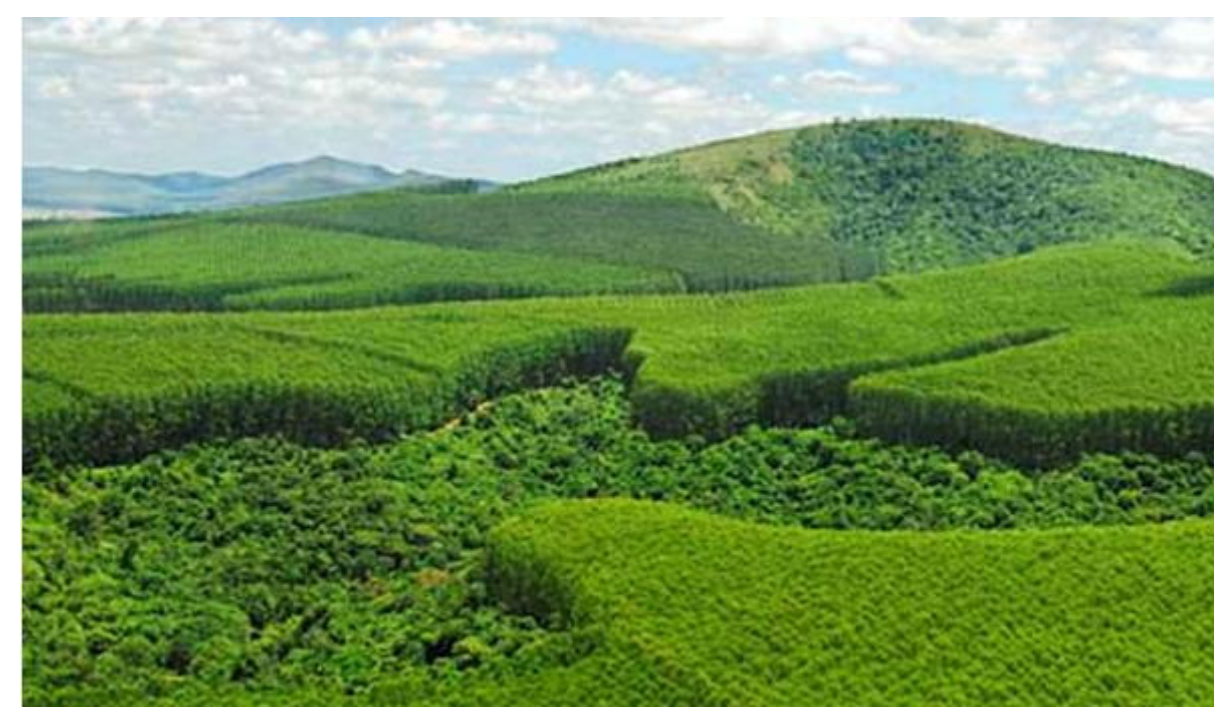

Figura 2. Foto de área de plantio de eucalipto e áreas de preservação, formando um mosaico florestal de produção e áreas de conservação.

Os solos da região tem baixa fertilidade, predominando os Argissolos Amarelos, com horizonte $B$ textural, textura média a argilosa e ocorrência freqüente de camada adensada em sub-superfície com alto grau de coesão. São encontrados ainda Latossolos Amarelo e Cambissolos, em menor ocorrência (GONÇALVES, 1975). As áreas de estudo apresentam, em sua maioria, relevo plano a suave ondulado.

A temperatura média anual é de $24{ }^{\circ} \mathrm{C}$, variando de $17{ }^{\circ} \mathrm{C}$ a $30{ }^{\circ} \mathrm{C}$ (média diária). A precipitação média da região é de $1.250 \mathrm{~mm}$, com extremos de $1.600 \mathrm{~mm}$ nas áreas próximas ao litoral e $1.000 \mathrm{~mm}$ a oeste. Em geral, a precipitação é bem distribuída ao longo do ano, não ocorrendo sazonalidade evidenciada na porção mais próxima ao litoral, sendo que é um pouco mais evidente na porção oeste da região de estudo (Figura 3). 


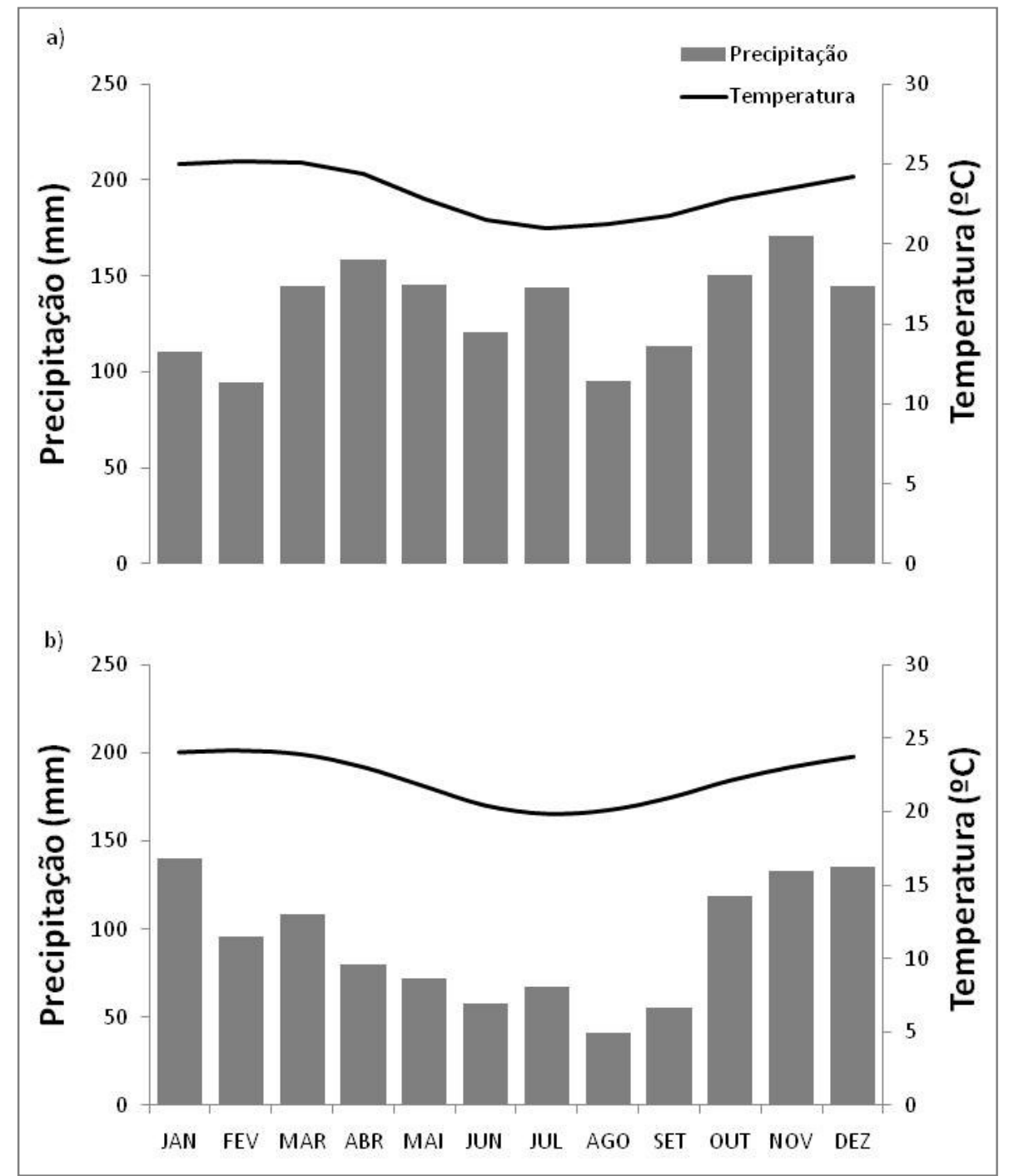

Figura 3. Média histórica de precipitação e temperatura para dois locais distintos da região a) Porto Seguro-BA, situado mais próximo ao litoral e b) Guaratinga-BA, situado nas áreas mais à oeste.

\subsection{Seleção dos talhões}

Foram selecionados para o estudo 90 talhões de plantios de Eucalyptus, estratificados em quatro classes de idade na época de avaliação (recém colhidos, 1 a 3 anos, 3 a 5 anos e 5 a 8 anos) e em três classes de tamanho de talhão (talhões pequenos, médios e grandes), A estratificação de tamanho dos talhões está melhor detalhada no item 4.4.1.1. 
A estratificação em classes de idade foi realizada para possibilitar a coleta do maior intervalo possível de valores de IAF, devido à variação desse parâmetro nas florestas de Eucalyptus estar altamente relacionada à idade (GIUNTI NETO et al., 2008). Já a estratificação do tamanho dos talhões teve como objetivo avaliar a influência de uma área de bordadura nos pixels avaliados na correlação entre os índices de vegetação e o IAF coletado em campo.

Para avaliar a eficácia da modelagem do IAF em função dos índices de vegetação, também foram utilizados dados de IAF pré-existentes ao estudo, coletados no ano de 2007, em nove talhões distribuídos ao longo das áreas de plantios florestais (denominados pontos de verificação).

Os talhões selecionados para o estudo (pontos de calibração) e as áreas de verificação do modelo (pontos de verificação) são apresentadas na Figura 4. 


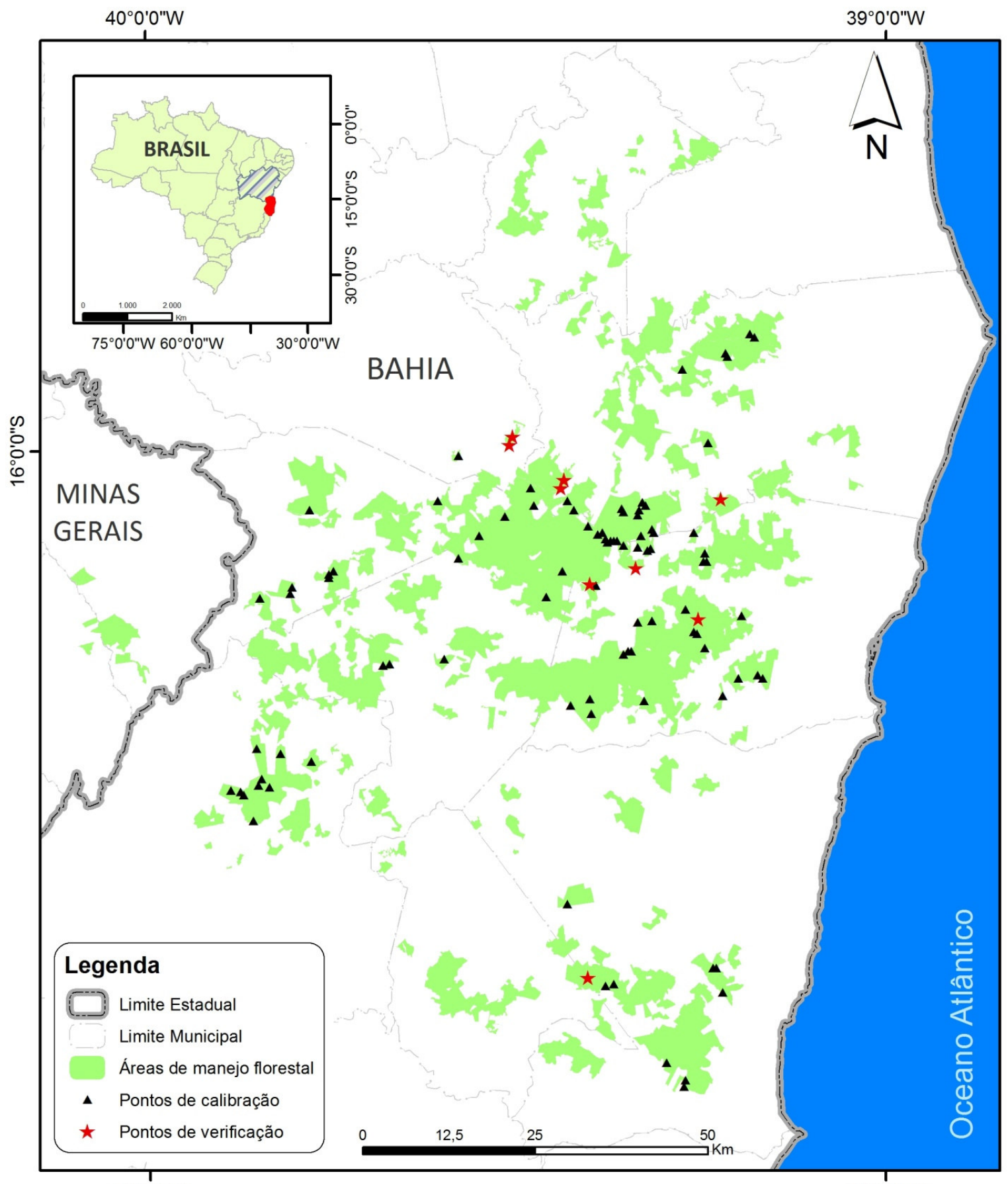

Figura 4. Localização das áreas de coleta de IAF em campo, para calibração e verificação do modelo em relação às áreas de manejo florestal da empresa (eucalipto e áreas de preservação). 


\subsection{Obtenção de dados de IAF em campo}

As coletas de IAF em campo foram realizadas entre os dias 16 de agosto de 2011 e 30 de agosto de 2011, através de fotos hemisféricas do dossel. Para obtenção das fotos hemisféricas, foram utilizados os seguintes equipamentos: tripé para suporte da câmera na altura de 1,30 m, câmera Sony Cybershot ${ }^{\circledR}$ DSC-F828 e lente FishEye Opteka ${ }^{\circledR}$ 0.22X AF e adaptador. Para cada talhão do estudo foram obtidas quatro fotos em duas posições em relação ao plantio: na linha de plantio e na entrelinha de plantio. As fotografias foram tiradas em condições de pouco vento e sem insolação direta. A câmera foi configurada para obter o maior contraste possível entre o dossel e o céu, visando melhores resultados no processamento das fotos. As fotos foram obtidas no local o mais próximo possível do centróide do pixel, com o auxílio de um GPS de navegação e mapas.

As fotos foram processadas no software Hemisfer ${ }^{\circledR}$, desenvolvido para avaliar fotos hemisféricas através da diferenciação de cada pixel da fotografia entre dossel ou céu e realizar o cálculo do índice de área foliar através de anéis concêntricos a partir do centro da imagem (Figura 5).

As configurações utilizadas na obtenção das fotografias e no processamento das imagens no software Hemisfer ${ }^{\circledR}$, foram as mesmas sugeridas por GIUNTI NETO (2007), que realizou um estudo para a calibração desse método na mesma região de estudo. 


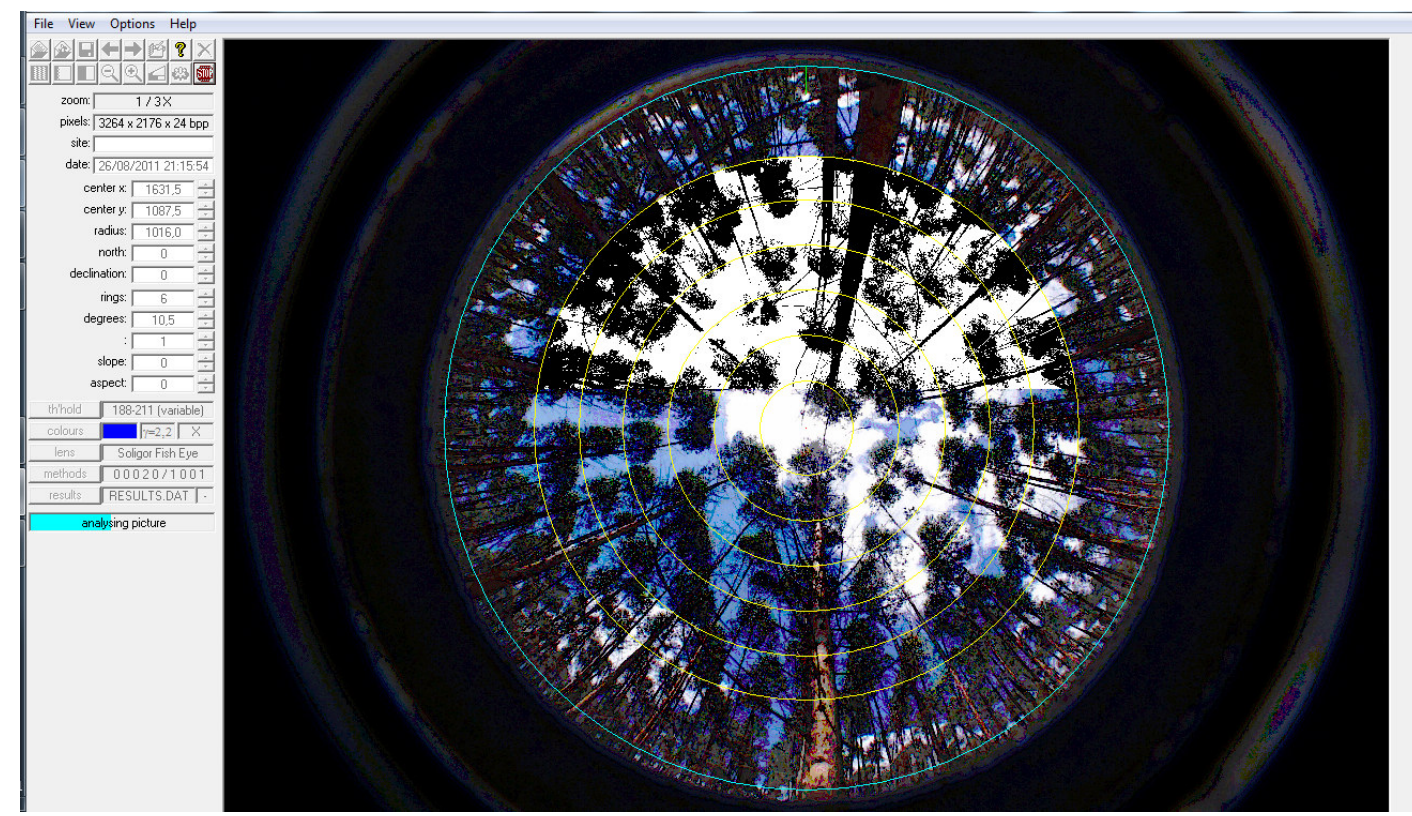

Figura 5. Avaliação de foto hemisférica para obtenção do IAF no software Hemisfer ${ }^{\circledR}$.

Também foram utilizados quinze talhões recém colhidos (cinco para cada classe de tamanho, conforme item 4.4.1.1) para representar os valores de IAF iguais a zero (Figura 6).

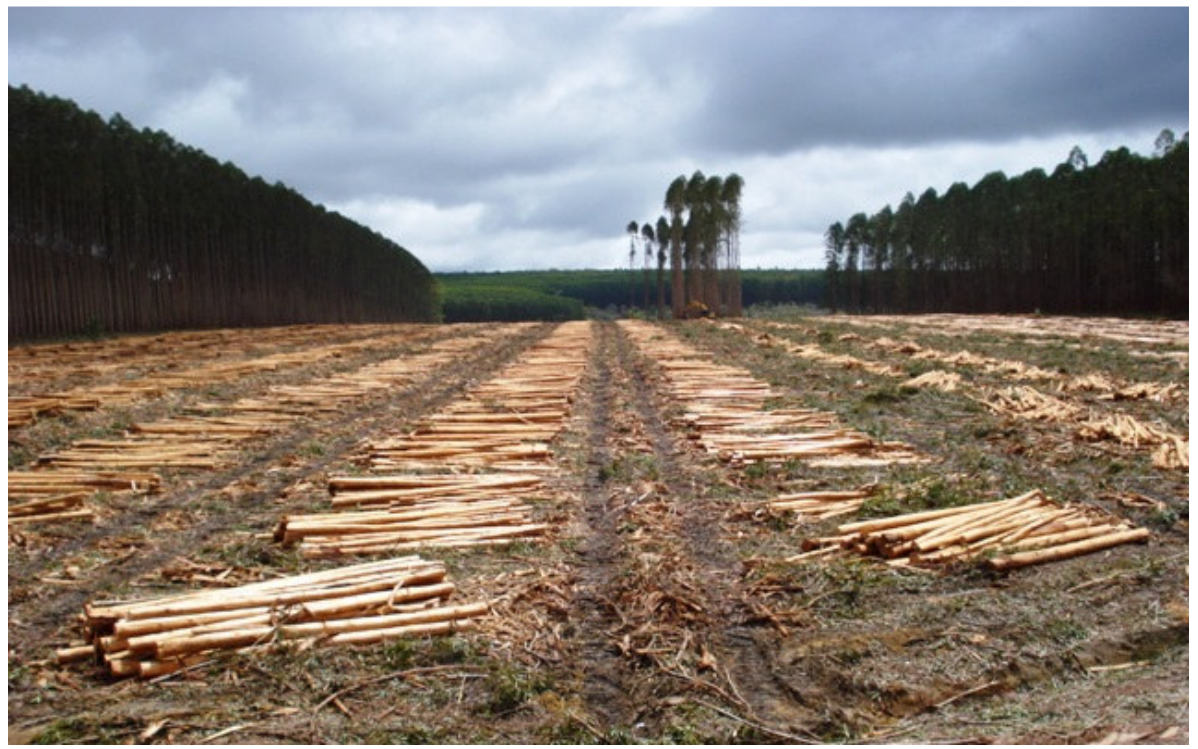

Figura 6. Talhão recém colhido, representando classe de IAF igual a zero. 


\subsection{Produto do sensor MODIS}

Foram utilizadas séries temporais do produto "Vegetation Indices 16-Day L3 Global 250m" do sensor MODIS dos satélites Terra e Aqua (códigos MOD13Q1 e MYD13Q1, respectivamente), entre os anos de 2002 (dia juliano 177) a 2011 (dia juliano 257), compreendendo 425 imagens (46 para cada ano). A cena utilizada foi a h14v10 (Figura 7).

Os produtos do sensor MODIS utilizados nesse trabalho possuem nível 3 de tratamento, ou seja, são imagens pré-processadas com correções geométricas, atmosféricas e radiométricas (RUDORFF et al., 2007). Outra característica dessas imagens é o mosaico temporal de 16 dias. Considerando que a taxa de revisita do sensor é de dois dias, os algoritmos de geração do produto selecionam o melhor valor no intervalo de 16 dias para cada pixel, visando a obtenção de uma imagem com a máxima redução possível do efeito de nuvens e resíduos de correções atmosféricas. O resumo do algoritmo de composição do mosaico temporal de 16 dias pode ser encontrado no trabalho de HUETE et al. (2002) ou na webpage do MODIS (http://modis.gsfc.nasa.gov/data/atbd/land_atbd.php).

Como foram utilizadas imagens dos dois satélites (Terra e Aqua), e a data de referência deles são alternadas, foi possível utilizar uma base com uma imagem a cada 8 dias. A resolução espacial nominal das imagens utilizadas foi de $250 \mathrm{~m}$.

As imagens utilizadas possuem o formato HDF ("Hierarchy Data Format"), contendo os índices de vegetação (NDVI e EVI), reflectâncias nas bandas do azul, vermelho, infravermelho próximo (IVP), centrados nos comprimentos de onda de 469 nm, $645 \mathrm{~nm}$ e $858 \mathrm{~nm}$, respectivamente. O cálculo dos índices de vegetação utilizados nesse trabalho são descritos no item 4.4.1.3.

Além dos índices de vegetação e reflectâncias, também são disponibilizados no produto dois índices de qualidade (resumido e detalhado), ângulo de visada, ângulo solar e data do imageamento. 


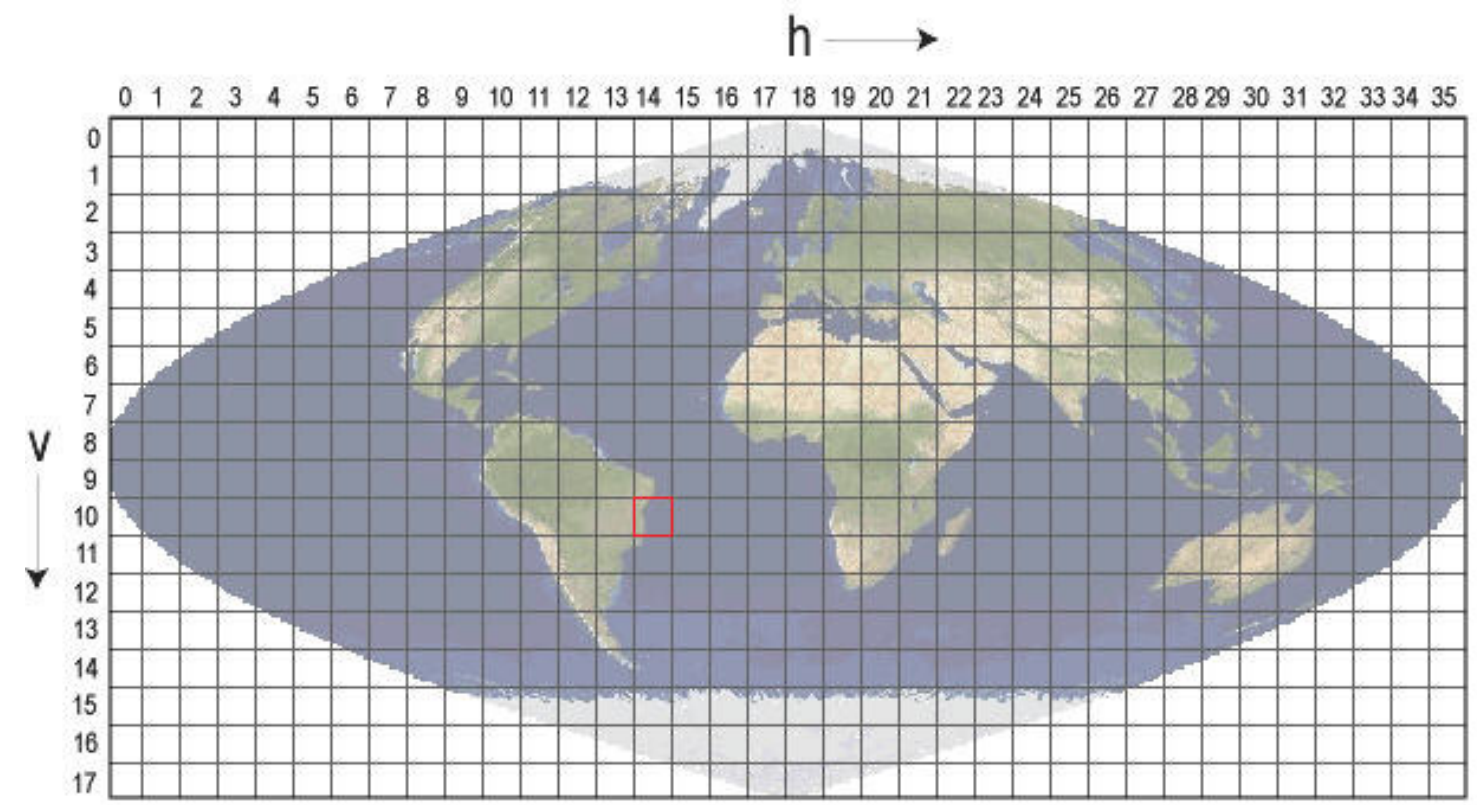

Figura 7. Grade de cenas do produtos MODIS de índice de vegetação com destaque para a cena utilizada (em vermelho).

\subsubsection{Processamento das imagens}

O processamento teve como objetivo a seleção de valores para as áreas de interesse, identificação dos pixels com os dados dos talhões de estudo e eliminação de valores inconsistentes, contemplando quatro etapas descritas a seguir:

\subsubsection{Extração dos dados das áreas de interesse}

Para extrair as informações de interesse das imagens para os alvos (talhões de eucaliptos), foi desenvolvida uma rotina utilizando a ferramenta "Model Builder" no software $\operatorname{ArcGIS}^{\circledR}$, seguindo os seguintes passos:

I) Adequação da projeção das imagens à base de dados utilizada no trabalho (limites dos talhões de plantios de eucalipto): A projeção utilizada pelos produtos MODIS é a sinusoidal, sendo necessário converter a projeção para a mesma utilizada na base de dados (sistema de projeção UTM, referencial geodésico SAD1969). 
II) Definição de quais pixels estão inteiramente contidos nos talhões estudados, quais contém misturas (eliminados do estudo) e estratificação em classes de tamanho dos talhões.

Para identificar os pixels de interesse e eliminar os pixels com mistura de uso do solo, foi usada a seguinte técnica: a) conversão da imagem em pontos, localizando os pontos no centróide do pixel; b) redução de área dos talhões através da eliminação de uma faixa de bordadura (Figura 8). e c) seleção dos pontos que estão contidos nas áreas reduzidas.

Através desse método, foi possível eliminar os pixels que continham mistura de informações de uso do solo. Os pixels selecionados foram estratificados em três categorias:

a) com redução de faixa de $100 \mathrm{~m}$ : em geral, são talhões pequenos onde os limites do pixel ficam bem próximos ao limite da área de interesse;

b) com redução de faixa de $150 \mathrm{~m}$ : há uma pequena área de bordadura para a área do pixel em relação ao talhão;

c) com redução de faixa de $250 \mathrm{~m}$ : em geral, os talhões são grandes (>30 ha) e os pixels estão bem centralizados na área, havendo uma bordadura considerável ao redor do pixel.

O formato da área ainda pode influenciar a faixa do talhão ao redor do pixel, porém, esse fator não foi considerado devido às dificuldades de encontrar talhões com formatos semelhantes. Exemplos dessa metodologia de trabalho são apresentados na Figura 8.

Essa estratificação foi importante para testar a eficiência dos índices de vegetação para áreas de diferentes tamanhos de alvos e verificar possíveis efeitos de ruídos de imageamento em decorrência de variações no ângulo de visada do sensor e incertezas de geolocalização, conforme mencionado por ANDERSON (2003). 
a)

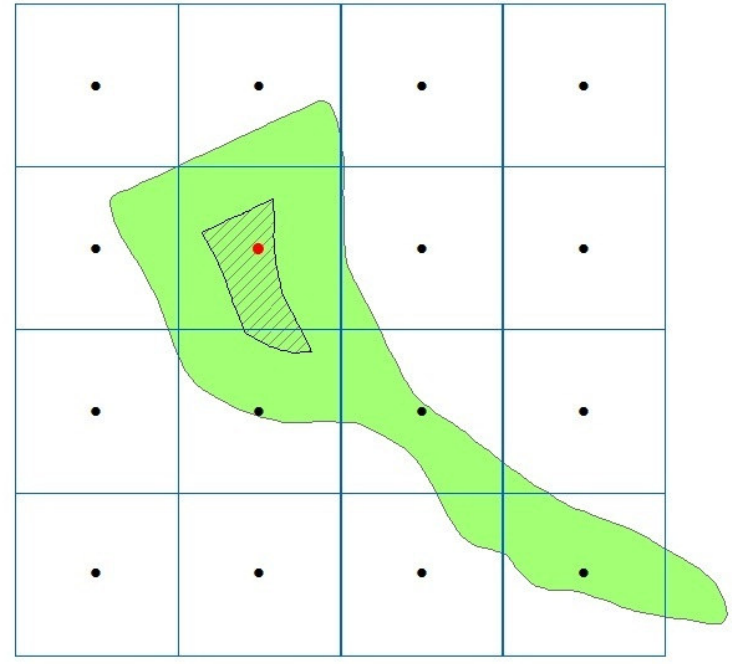

b)

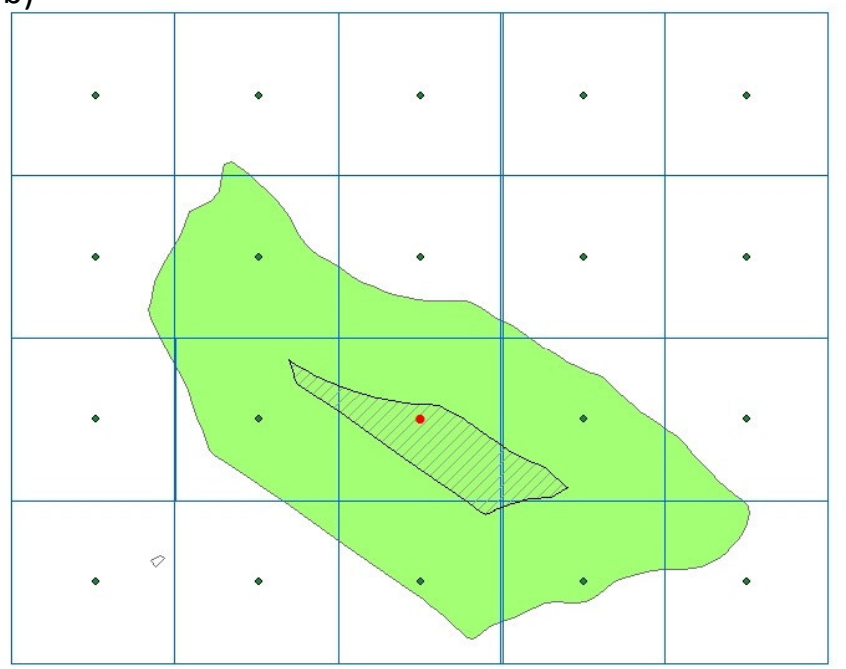

c)
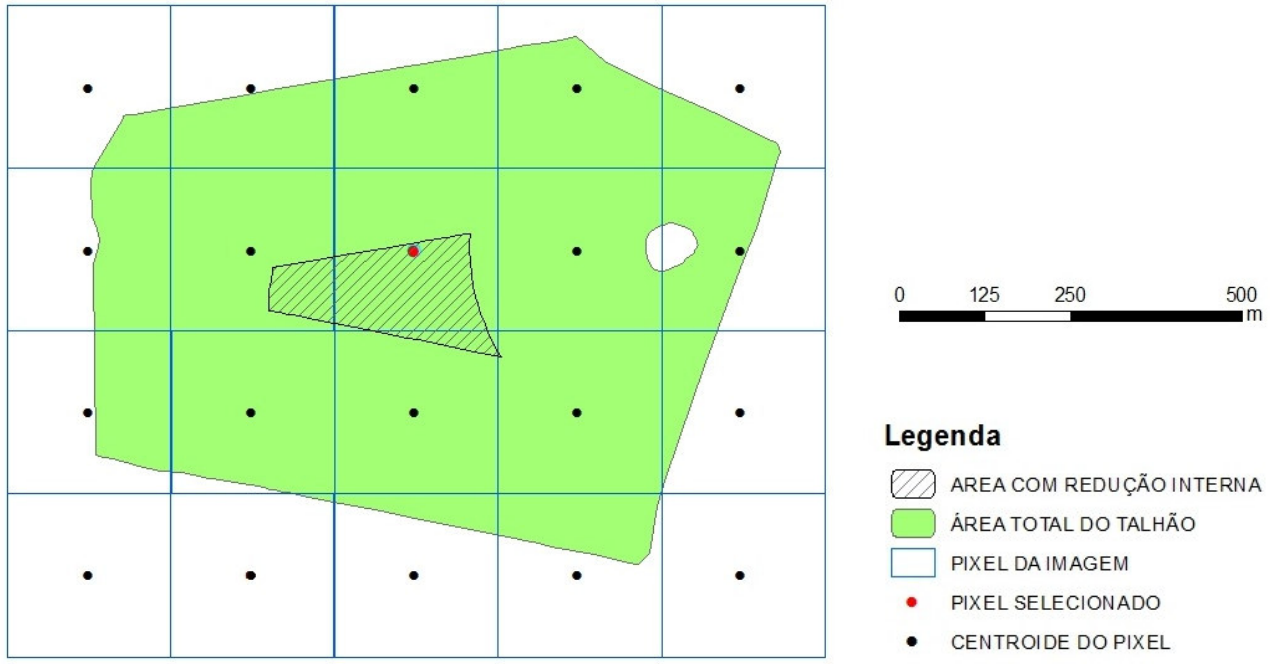

\section{Legenda}

Z AREA COM REDU ÇÃO INTERNA ÁREA TOTAL DO TALHÃO PIXEL DA IMAGEM

- pixel selecionado

- centroide do pixel

Figura 8. Exemplo da aplicação da metodologia de identificação dos pixels de interesse e estratificação em relação ao tamanho do talhão: a) com redução de $100 \mathrm{~m}$ de faixa, b) $150 \mathrm{~m}$ e c) $250 \mathrm{~m}$. 
III) Cruzamento de informações dos pixels (reflectâncias e índices de vegetação) com a identificação das áreas de estudo, como por exemplo, áreas de plantio de eucalipto (com dados de dia de plantio, material genético, entre outros), áreas de preservação e reserva legal, e também a data de referência das imagens. Para facilitar a estruturação do banco de dados, as informações relativas às imagens foram associadas às referências dos alvos (talhões) e data da informação (imagem) em um único arquivo (shapefile) de pontos.

\subsubsection{Geração dos índices de vegetação}

Através dos dados de reflectância (azul, vermelho e infravermelho), foram geados dois índices de vegetação, visando comparar a eficiência dos índices:

\section{NDVI}

O NDVI ("Normalized Difference Vegetation Index"), ou Indice de Vegetação por Diferença Normalizada, é um índice que considera a razão entre a diferença e soma da reflectância na região do infravermelho próximo ( $\rho_{\mathrm{IVP}}$ ) e a reflectância na região espectral do vermelho $\left(\rho_{v}\right)$, descrita na Eq. (1):

$$
N D V I=\left(\rho_{\text {IVP }}-\rho_{V}\right) /\left(\rho_{\text {IVP }}+\rho_{V}\right)
$$

\section{EVI}

O EVI ("Enhanced Vegetation Index"), ou Índice de Vegetação Realçado, é um índice gerado a partir de informações de reflectância nas bandas do azul $\left(\rho_{A}\right)$, infravermelho próximo $\left(\rho_{\mathrm{IVP}}\right)$ e vermelho $\left(\rho_{\mathrm{V}}\right)$, além de fatores de ajuste do solo e ganho e ajuste de efeitos de aerossóis da atmosfera. O cálculo é descrito na Eq. (2): 


$$
E V I=G\left(\rho_{I V P}-\rho_{V}\right) /\left(L+\rho_{I V P}+C 1 \rho_{V}-C 2 \rho_{A}\right)
$$

Onde, G é o fator de ganho, L é o fator de ajuste para o solo e C1 e C2 são os coeficientes de ajuste para efeito de aerossóis da atmosfera. Os valores dos coeficientes adotados no algoritmo do MODIS são: $L=1, G=2,5, C 1=6$ e C2=7,5.

\subsubsection{Tratamento da série temporal}

A consistência de dados da série temporal de índices de vegetação foi realizada em duas etapas distintas:

a) Identificação e eliminação de valores de índice de vegetação altamente discrepantes, geralmente causados por interferência de nuvens e da atmosfera.

Nessa etapa, foram testados três métodos de identificação e eliminação de valores inconsistentes:

I) Utilizando o índice de qualidade resumido que acompanha cada pixel do produto de índice de vegetação do MODIS (MOD13Q1 e MYD13Q1), sabendo-se que existem quatro níveis neste índice: 0- dados confiáveis, 1- dados marginais utilizáveis com restrição, 2- alvo coberto com neve ou gelo e 3- alvos com interferência de nuvens. Nesse item, foram excluídos os dados com o índice 3 (não houve dados com o índice 2).

II) Também utilizando as informações de qualidade do pixel do MODIS, porém, excluindo os dados com índice 1 e 3 ;

III) Adaptação do método proposto por FREITAS et al. (2011), que utilizaram uma filtragem inicial excluindo informações de pixels com valores maiores do que $10 \%$ de reflectância na banda do azul. A adaptação do método para esse estudo consistiu em utilizar, além da banda do azul, os valores da banda do 
vermelho, para determinar valores inconsistentes e gerar a informação de índice de confiabilidade do pixel, baseando-se nas observações do comportamento das séries temporais e no comportamento espectral das florestas de eucalipto. Estes alvos tem a peculiaridade de sofrer uma variação grande de nível de vegetação durante o ciclo, variando de valores próximos a zero (encontrados logo após a colheita e início de um novo plantio, até valores máximos de 4 a $6 \mathrm{~m}^{2} / \mathrm{m}^{2}$ no auge do seu desenvolvimento (BEADLE \& TURNBULL, 1992; XAVIER, SOARES \& ALMEIDA, 2002; GIUNTI NETO et al., 2008). Portanto, foi utilizado um critério que visou abranger ambas as situações:

- quando os valores de reflectância da banda do vermelho forem menores do que 6\% (em geral, observam-se que esses valores ocorrem quando a floresta está estabelecida, ou seja, há pouca ou quase nenhuma reflectância do solo), e se os valores da banda do azul forem maiores do que 3,5\% há um indicativo de que há interferência de nuvens e os dados são considerados inconsistentes; e

- para os casos em que a reflectância da banda do vermelho for maior do que $6 \%$ (em geral, ocorrendo quando os valores de IAF são muito baixos ou nulos, ou seja, quando a floresta de eucalipto é colhida e no início do desenvolvimento de um novo plantio), os valores da banda do azul que indicam uma possível interferência atmosférica passam a ser na ordem $8 \%$, devido a florestas nas condições de IAF baixo ou nulo apresentarem maior reflectância na banda do azul.

Para avaliar a eficiência dos métodos de identificação de consistência, foram selecionadas dez áreas de plantios com valores mais constantes de IAF (floresta adulta) em uma amostragem de três anos, para avaliar as alterações no coeficiente de variação dos índices de vegetação. Para essa verificação, foi escolhido somente um índice de vegetação (NDVI), visando facilitar as análises. 
b) Pós-processamento da série temporal

O objetivo dessa etapa foi suprimir eventuais dados inconsistentes que não foram eliminados na etapa anterior e, principalmente, reduzir variações de curta escala temporal, que não refletem as alterações de IAF no dossel da floresta, mas sim originadas por diferenças entre ângulo de visada do satélite e resíduos da correção atmosférica.

Para esse pós-processamento, foi utilizado o filtro de Savitzky-Golay, que consiste no ajuste de uma função aos dados originais visando a suavização da série temporal, visando aproximar-se o máximo possível da variação natural do IAF.

Para aplicar o filtro de Savitzky-Golay, foi utilizado o software TIMESAT $^{\oplus}$ 3.0 (JÖNSSON \& EKLUNDH, 2004), desenvolvido para realizar análises de séries temporais de sensores remotos. Além da aplicação do filtro, o TIMESAT $^{\oplus}$ possui diferentes métodos para detectar e remover outliers positivos e negativos que podem ter impactos significativos na função ajustada. Nesse trabalho foi utilizado o método que verifica valores da série temporal que sejam consideravelmente diferentes da média dos vizinhos anteriores e posteriores, atribuindo a esses dados um peso zero no processamento (no software chamado de spike method, onde foi utilizado o método Median Filter).

Através desse software foi possível utilizar ainda os indicadores de confiabilidade dos dados gerados no item anterior (4.4.1.4), permitindo que o processamento fosse realizado somente com os valores mais confiáveis, melhorando a suavização da série temporal. Nesse software, ao abrir o arquivo de série temporal, também é possível abrir um arquivo auxiliar com os respectivos índices de qualidade ou pesos, para trabalhar somente com valores mais confiáveis

O método proposto por SAVITZKY \& GOLAY (1964), apud YUAN et al. (2011), basea-se em uma suavização da série temporal, através de um ajuste polinomial de grau variável obtido pelo método dos mínimos quadrados, para cada 
ponto da série em uma janela móvel. YUAN et al. (2011) utilizaram esse método para aprimorar o produto de IAF disponibilizado pelo MODIS, conseguindo melhoras significativas principalmente em áreas de floresta e com alta incidência de nuvens, como é o caso da área em estudo desse trabalho.

O valor do intervalo da janela móvel pode ser ajustado no software, sendo que esse valor determina o grau de suavização da série temporal, porém, afetando também a capacidade da curva ajustada seguir uma rápida mudança no padrão dos dados (JÖNSSON \& EKLUNDH, 2004). Nesse estudo, foi utilizado o valor 15 para esse parâmetro, buscando que a suavização pudesse eliminar variações bruscas (inconsistentes) sem perder a capacidade de representar a queda do IAF quando realizada a colheita das florestas.

\subsubsection{Estruturação da base de dados}

As informações geradas em shapefile foram transferidas para um banco de dados estruturado no Microsoft ${ }^{\circledR}$ Access, contendo as informações das áreas de interesse, data da imagem, reflectâncias, índices de vegetação e índice de confiabilidade do pixel. Os dois últimos foram gerados posteriormente, utilizando-se os valores de reflectância, cuja metodologia está detalhada nos itens 4.4.1.3 e 4.4.1.4 (índices de vegetação e índice de confiabilidade do pixel, respectivamente). Também, foram incluídas as informações pós processadas, como série temporal tratada e IAF estimado.

\subsection{Análise de dados e verificação do modelo}

A análise de dados consistiu em realizar regressões que melhor se ajustassem aos dados de índices de vegetação e índices de área foliar coletados em campo, avaliando o coeficiente de determinação $\left(R^{2}\right)$, o erro médio quadrático 
(RMSE) e o valor-p (sendo considerado significativo para $p<0,05$ e indicado quando $p<0,001)$.

Para avaliar a eficácia do modelo para obtenção do IAF em função do índice de vegetação, foram utilizados dados de IAF de campo de nove locais, coletados anteriormente ao estudo (no ano de 2007), possibilitando avaliar também a eficácia do tratamento da série temporal com o filtro de Savitzky-Golay. Esses dados foram coletados através de amostras destrutivas, sendo que os detalhes da amostragem podem ser encontrados no trabalho de GIUNTI NETO et al. (2008).

Os dados de campo para verificação foram comparados com os valores estimados após o tratamento das séries temporais do índice de vegetação com o filtro Savitzky-Golay e da transformação dos dados de índice de vegetação em IAF. 


\section{RESULTADOS E DISCUSSÃO}

\subsection{Dados de IAF obtidos em campo}

Os dados de IAF obtidos em coletas de campo, para as áreas de calibração do modelo, apresentaram IAF médio de $2,7 \mathrm{~m}^{2} / \mathrm{m}^{2}$, variando de 1,3 a $5,7 \mathrm{~m}^{2} / \mathrm{m}^{2}$. Foi observada uma correlação entre o IAF e a idade da floresta (Figura 9), comprovando que a estratificação da coleta por idades é efetiva para alcançar um maior intervalo de valores de IAF.

O decréscimo dos valores IAF com o aumento a idade também foi encontrado em outros trabalhos, como XAVIER, SOARES \& ALMEIDA (2002), STAPE et al. (2008) e GIUNTI NETO et al. (2008). Esse comportamento afeta significativamente as taxas de fotossíntese e, consequentemente, a produtividade de madeira dos plantios de eucalipto (STAPE et al., 2008), sendo que suas causas ainda são objetos de estudo atualmente.

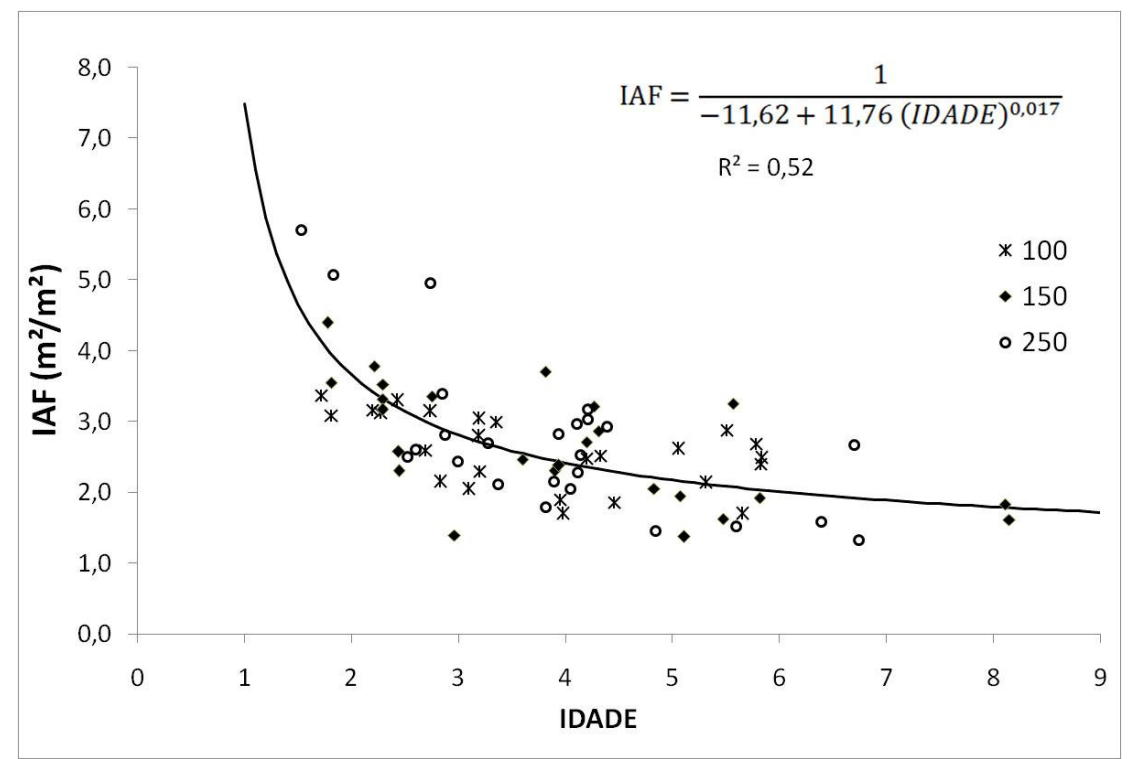

Figura 9. IAF coletado em campo em relação à idade da floresta em anos, mostrando o decréscimo dos valores de IAF com o estabelecimento da floresta. 


\subsection{Extração de dados do MODIS para áreas de interesse}

A metodologia de extração dos pixels das imagens do MODIS para as áreas de interesse (plantios de eucalipto), visando selecionar somente os pixels que estivessem inteiramente contidos dentro dos alvos, foi realizada não só para os talhões selecionados para esse estudo, mas também para toda a área de plantio de eucalipto da região de estudo.

Com essa informação, foi possível avaliar a representatividade do produto MODIS para os plantios de eucalipto da região, assim como para os diversos níveis de tamanhos de alvos (conforme apresentado no item 4.4.1.1).

Observa-se na Tabela 1, que do total das áreas disponíveis para o plantio de Eucalyptus na região (108,4 mil ha), 50,4\% (54,7 mil ha) podem ser representados por conter inteiramente um ou mais pixels do produto MODIS para índice de vegetação. Observa-se, também, que a maior parte $(29,7 \%)$ desses talhões são da classe de menor tamanho, ou seja, podem ser representados por um pixel mas sem uma área representativa ao redor (bordadura). Isso reforça a importância de ser avaliada a efetividade de representação para os pixels incluídos nos talhões de menor tamanho, visando uma maior cobertura na aplicação do método proposto nesse estudo.

Tabela 1. Áreas representadas pelos pixels do MODIS, com estratificação pelo tamanho dos talhões e áreas não representadas.

\begin{tabular}{crc}
\hline Classe de tamanho dos alvos & Área (ha) & (\% do total) \\
\hline 100 & $32.264,15$ & 29,7 \\
\hline 150 & $15.887,32$ & 14,6 \\
\hline 250 & $6.540,31$ & 6,0 \\
\hline Total das áreas representadas & $\mathbf{5 4 . 6 9 1 , 7 8}$ & $\mathbf{5 0 , 4}$ \\
\hline \multicolumn{3}{c}{} \\
\hline Área não representadas & $\mathbf{5 3 . 7 7 9 , 2 2}$ & $\mathbf{4 9 , 6}$ \\
\hline Área total & $\mathbf{1 0 8 . 4 7 1 , 0 0}$ & $\mathbf{1 0 0}$ \\
\hline
\end{tabular}


Na Figura 10 é mostrada a espacialização dos talhões que possuem um ou mais pixels representativos e as áreas que não possuem, ou seja, contém pixels com mistura de informações.

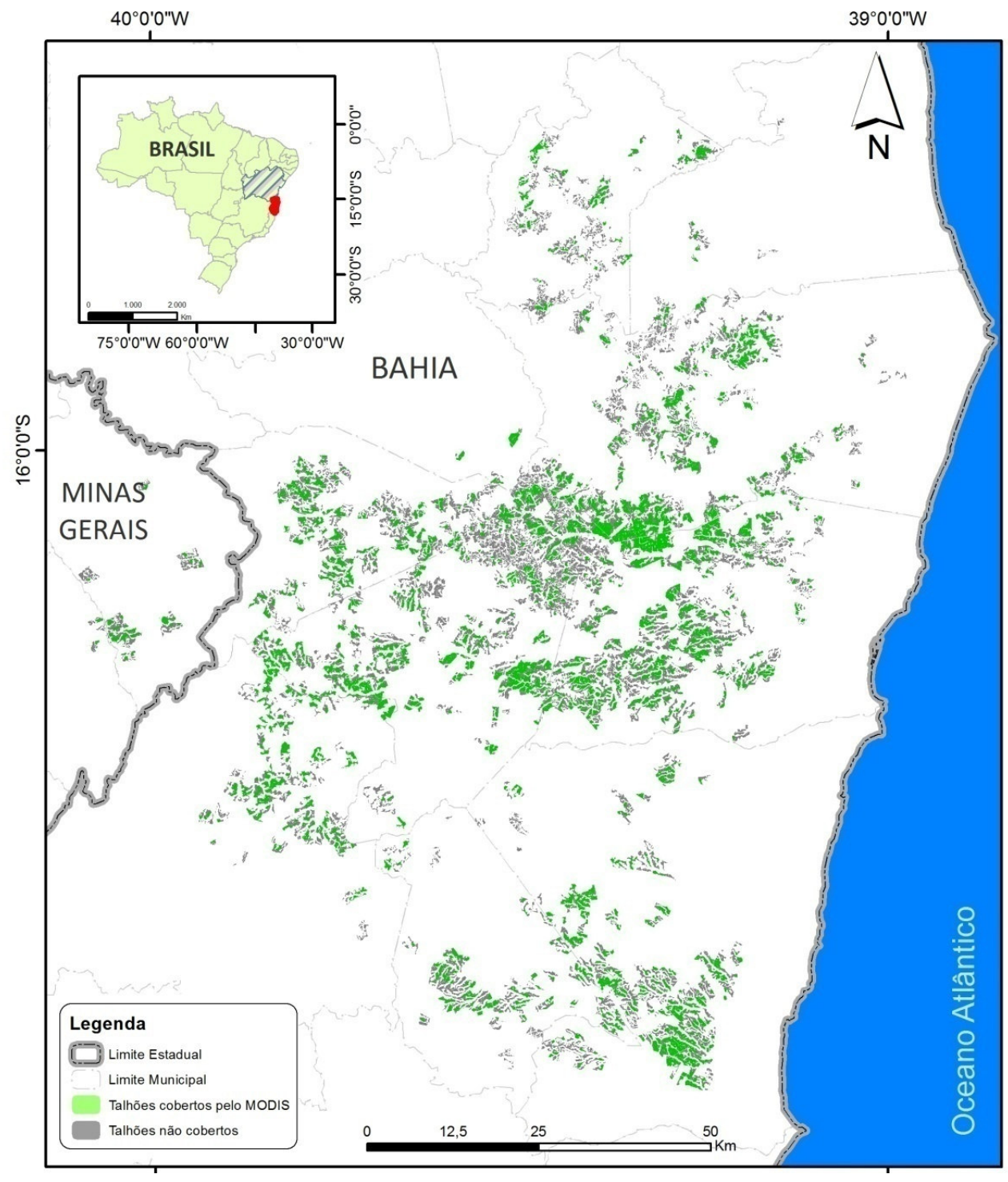

Figura 10. Espacialização das áreas disponíveis para plantio representadas no estudo (cobertas pelo MODIS) em verde, e as áreas não representadas (em cinza). 


\subsection{Tratamento da série temporal}

Os resultados dos métodos de definição do índice de qualidade do pixel, ou seja, se o valor de leitura do pixel é confiável ou não, são exibidos nas Tabelas 2, 3 e 4, com um exemplo detalhado na Figura 11.

Observa-se na Tabela 2 que, utilizando as informações do índice de qualidade resumido do pixel (IQ) que acompanha o produto MODIS, os resultados não foram satisfatórios. Com a retirada somente das informações com IQ = 3 (dados com interferência de nuvens), o coeficiente de variação (CV) sofreu uma redução muito baixa (de 15 para 14\%). Como se pode confirmar no exemplo da Figura 11, restaram alguns valores discrepantes na série temporal. Com a retirada de dados marcados com o IQ = 1 e 3 (dados marginais e com interferência de nuvens), o CV foi reduzido consideravelmente (de 15 para 9\%), porém, a quantidade de informação retirada foi muito alta (em média 70\%), o que é não é interessante para análises temporais, visto que resulta em uma série com grandes lacunas.

Tabela 2. Resumo da aplicação do filtragem usando o IQ (1) do MODIS.

\begin{tabular}{c|ccc|ccc}
\hline & \multicolumn{3}{|c|}{ Dados originais } & \multicolumn{3}{c}{ Retirada de IQ = 3 } \\
\hline & NDVI & & & NDVI & $\%$ \\
Local & médio & N & CV & médio & Retirada & CV \\
\hline FOM062-00301 & 0,764 & 138 & $16 \%$ & 0,766 & $7 \%$ & $16 \%$ \\
FOM065-00201 & 0,787 & 138 & $16 \%$ & 0,796 & $9 \%$ & $15 \%$ \\
FOM070-00201 & 0,831 & 138 & $15 \%$ & 0,840 & $7 \%$ & $13 \%$ \\
FOM070-00501 & 0,790 & 138 & $15 \%$ & 0,795 & $5 \%$ & $14 \%$ \\
VCC026-02501 & 0,805 & 138 & $16 \%$ & 0,814 & $4 \%$ & $15 \%$ \\
VCC026-03201 & 0,777 & 138 & $13 \%$ & 0,786 & $7 \%$ & $12 \%$ \\
VCC027-01801 & 0,828 & 138 & $14 \%$ & 0,843 & $8 \%$ & $11 \%$ \\
VCC076-04001 & 0,813 & 138 & $14 \%$ & 0,822 & $5 \%$ & $12 \%$ \\
VCC108-00701 & 0,828 & 138 & $14 \%$ & 0,836 & $7 \%$ & $13 \%$ \\
VCC114-00401 & 0,789 & 138 & $15 \%$ & 0,793 & $7 \%$ & $14 \%$ \\
\hline Média & $\mathbf{0 , 8 0 1}$ & & $\mathbf{1 5 \%}$ & $\mathbf{0 , 8 0 9}$ & $\mathbf{7 \%}$ & $\mathbf{1 4 \%}$ \\
\hline
\end{tabular}


Tabela 3. Resumo da aplicação do filtragem usando o IQ (1 e 3) do MODIS.

\begin{tabular}{c|ccc|ccc}
\hline & \multicolumn{3}{|c|}{ Dados originais } & \multicolumn{3}{c}{ Retirada de IQ = 3 e 1 } \\
\hline & NDVI & & & NDVI & $\%$ & \\
Local & médio & $\mathbf{N}$ & CV & médio & Retirada & CV \\
\hline FOM062-00301 & 0,764 & 138 & $16 \%$ & 0,769 & $64 \%$ & $12 \%$ \\
FOM065-00201 & 0,787 & 138 & $16 \%$ & 0,826 & $74 \%$ & $7 \%$ \\
FOM070-00201 & 0,831 & 138 & $15 \%$ & 0,829 & $73 \%$ & $13 \%$ \\
FOM070-00501 & 0,790 & 138 & $15 \%$ & 0,808 & $70 \%$ & $6 \%$ \\
VCC026-02501 & 0,805 & 138 & $16 \%$ & 0,822 & $64 \%$ & $10 \%$ \\
VCC026-03201 & 0,777 & 138 & $13 \%$ & 0,791 & $70 \%$ & $8 \%$ \\
VCC027-01801 & 0,828 & 138 & $14 \%$ & 0,863 & $72 \%$ & $6 \%$ \\
VCC076-04001 & 0,813 & 138 & $14 \%$ & 0,829 & $66 \%$ & $10 \%$ \\
VCC108-00701 & 0,828 & 138 & $14 \%$ & 0,846 & $74 \%$ & $7 \%$ \\
VCC114-00401 & 0,789 & 138 & $15 \%$ & 0,815 & $70 \%$ & $9 \%$ \\
\hline Média & $\mathbf{0 , 8 0 1}$ & & $\mathbf{1 5 \%}$ & $\mathbf{0 , 8 2 0}$ & $\mathbf{7 0 \%}$ & $\mathbf{9 \%}$ \\
\hline
\end{tabular}

Na Tabela 4 são mostrados os resultados do índice de confiabilidade baseados nas bandas do azul e vermelho, proposto nesse estudo. Observa-se o índice obteve boa performance, pois apresentou uma redução considerável no CV (de 15 para $11 \%$ ) com uma taxa relativamente baixa de dados excluídos (em média $22 \%$ ). No exemplo da Figura 11, observa-se que houve a exclusão de grande parte dos valores altamente discrepantes.

Outro ponto importante, foi o aumento na média geral do índice de vegetação em relação aos dados originais (de 0,801 para 0,846, em média). Esse aumento reflete a qualidade do filtro aplicado, pois a tendência é que os efeitos atmosféricos (nuvens e gases) ou sombra, influenciem na redução (muitas vezes brusca) dos índices de vegetação gerados a partir de equações baseadas na diferença entre a reflectância do vermelho e infra-vermelho. 
Tabela 4. Resumo da aplicação do filtragem usando o índice de confiabilidade proposto.

\begin{tabular}{|c|c|c|c|c|c|c|}
\hline \multirow[b]{2}{*}{ Local } & \multicolumn{3}{|c|}{ Dados originais } & \multicolumn{3}{|c|}{$\begin{array}{c}\text { Índice de confiabilidade do } \\
\text { pixel proposto }\end{array}$} \\
\hline & $\begin{array}{l}\text { NDVI } \\
\text { médio }\end{array}$ & $\mathbf{N}$ & CV & $\begin{array}{l}\text { NDVI } \\
\text { médio }\end{array}$ & $\begin{array}{c}\% \\
\text { Retirada }\end{array}$ & CV \\
\hline FOM062-00301 & 0,764 & 138 & $16 \%$ & 0,778 & $17 \%$ & $12 \%$ \\
\hline FOM065-00201 & 0,787 & 138 & $16 \%$ & 0,816 & $30 \%$ & $11 \%$ \\
\hline FOM070-00201 & 0,831 & 138 & $15 \%$ & 0,859 & $17 \%$ & $8 \%$ \\
\hline FOM070-00501 & 0,790 & 138 & $15 \%$ & 0,805 & $20 \%$ & $12 \%$ \\
\hline VCC026-02501 & 0,805 & 138 & $16 \%$ & 0,832 & $24 \%$ & $12 \%$ \\
\hline VCC026-03201 & 0,777 & 138 & $13 \%$ & 0,794 & $21 \%$ & $11 \%$ \\
\hline VCC027-01801 & 0,828 & 138 & $14 \%$ & 0,851 & $20 \%$ & $10 \%$ \\
\hline VCC076-04001 & 0,813 & 138 & $14 \%$ & 0,839 & $24 \%$ & $9 \%$ \\
\hline VCC108-00701 & 0,828 & 138 & $14 \%$ & 0,846 & $21 \%$ & $11 \%$ \\
\hline VCC114-00401 & 0,789 & 138 & $15 \%$ & 0,820 & $25 \%$ & $10 \%$ \\
\hline Média & 0,801 & & $15 \%$ & 0,824 & $22 \%$ & $11 \%$ \\
\hline
\end{tabular}

Os melhores resultados encontrados no índice proposto, em relação aos índices disponibilizados pelo produto MODIS podem ser explicados pelo fato de que os índices gerados pelo MODIS são mais generalistas, e foram desenvolvidos para atender uma grande diversidade de alvos. Já para o índice proposto, foi utilizada uma metodologia direcionada ao comportamento espectral do plantio de Eucalyptus, também considerando também sua variação natural, o que favorece a qualidade da filtragem de informações confiáveis. 
a)

Dados originais

O) Dados restantes após a filtragem

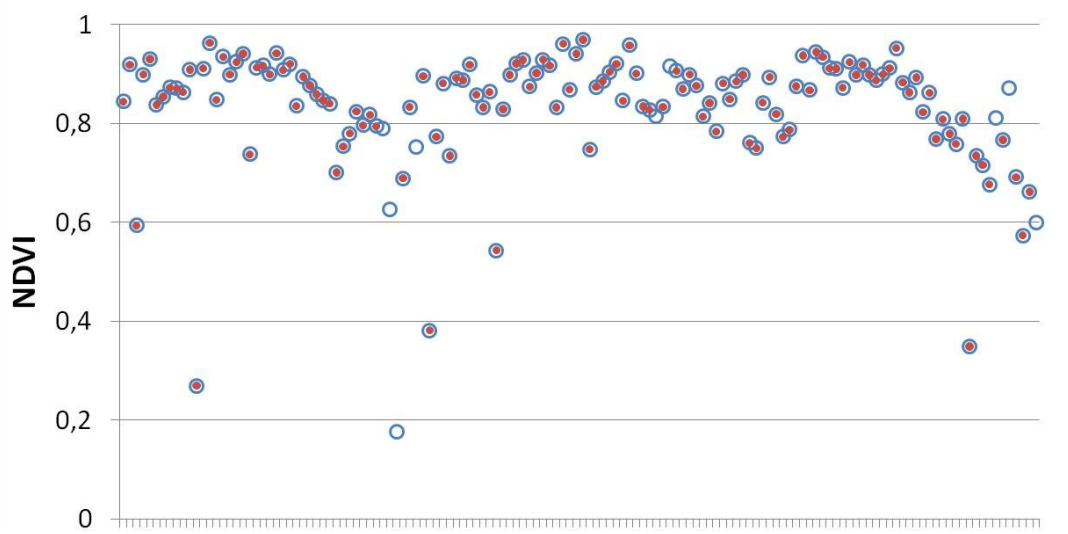

b)

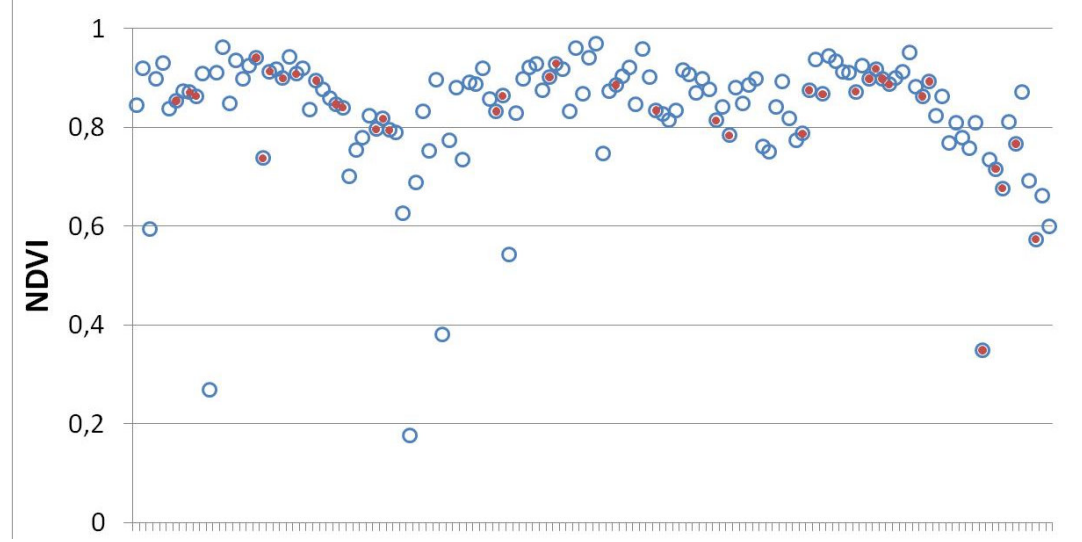

c)

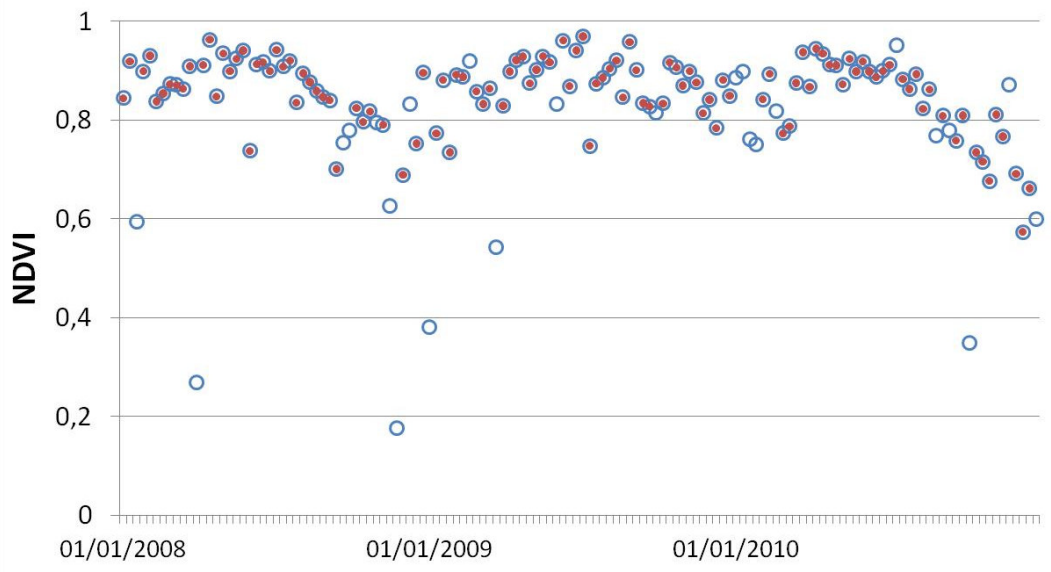

Figura 11. Exemplo da aplicação dos filtros testados para retirada de valores inconsistentes, sendo a) retirada do IQ do MODIS $=1$, b) retirada do IQ do MODIS $=1$ e 3 e c) índice de confiabilidade proposto. 


\subsection{Relações entre índices de vegetação e IAF}

A resposta do IAF ao NDVI, considerando também os valores nulos (resposta do solo), ajustou-se melhor a um modelo exponencial, conforme observase na Figura 12 e 13.

Não foi observada uma diferença evidente para os ajustes entre as classes de tamanho de talhão utilizadas, conforme observa-se na Tabela 5. O coeficiente de determinação aumenta dos talhões com classe de tamanho 100 para classe $150(0,78$ para 0,90 , respectivamente) porém, decresce nos talhões de classe $200(0,80)$. O erro médio quadrático (RMSE) segue uma leve tendência de queda em relação aos tratamentos $\left(1,12,1,08\right.$ e 1,02 m²/ $\mathrm{m}^{2}$, para 100,150 e 250, respectivamente). Porém, essas diferenças podem estar mais associadas a incertezas de outras naturezas que não ao tamanho do talhão, como por exemplo, incerteza nas medições em campo, influências de fundo de dossel, como ervas daninhas, ou resíduos da correção atmosférica, visto que a diferença entre os coeficientes de determinação RMSE é muito baixa.

Visto que a diferença entre as regressões não foi significativa, utilizou-se uma única regressão para todo o conjunto de valores de IAF (Figura 13), com coeficiente de determinação de 0,80 e RMSE de $1,16 \mathrm{~m}^{2} / \mathrm{m}^{2}$.

Segundo HUETE et al. (2002), uma das principais desvantagens do NDVI é a não-linearidade inerente, por ser um índice baseado na razão de bandas, assim como a influência aditiva dos ruídos. O NDVI apresenta ainda problemas de escala (HUETE, 1988) com a saturação do sinal nos valores mais elevados de IAF, o que também foi observado nesse estudo. O ajuste exponencial da regressão tende a criar uma superestimação no IAF, para valores de NDVI mais elevados. 


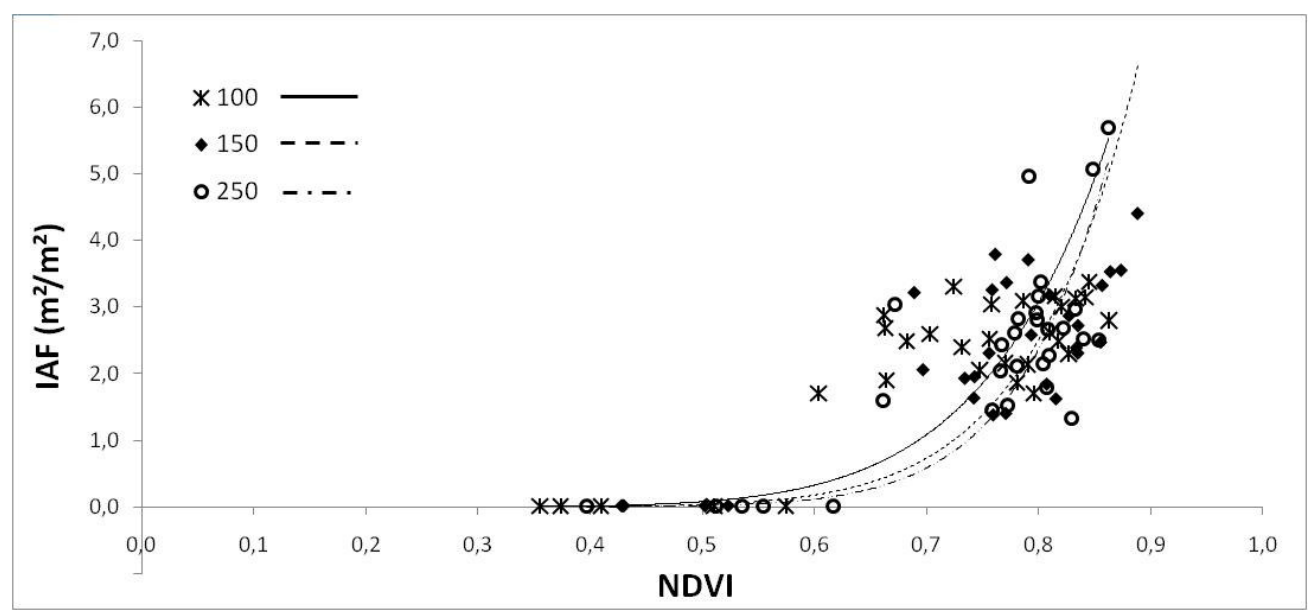

Figura 12. Relação entre IAF medido e NDVI, para os três tratamentos testados.

Tabela 5. Equações ajustadas para a relação entre IAF e NDVI , coeficiente de determinação $\left(R^{2}\right)$, erro médio quadrático (RMSE) e valor-p para os tratamentos analisados.

\begin{tabular}{clccc}
\hline Tratamento & Equação ajustada & $\mathbf{R}^{\mathbf{2}}$ & RMSE & Valor-p \\
\hline 100 & $\mid \mathrm{AF}=17,559 * \mathrm{NDVI}^{7,8072}$ & 0,78 & 1,12 & $<0,001$ \\
\hline 150 & $\mid \mathrm{AF}=19,684 * \mathrm{NDVI}^{9,2285}$ & 0,90 & 1,08 & $<0,001$ \\
\hline 250 & $\mid \mathrm{AF}=24,605 * \mathrm{NDVI}^{10,485}$ & 0,80 & 1,02 & $<0,001$ \\
\hline
\end{tabular}

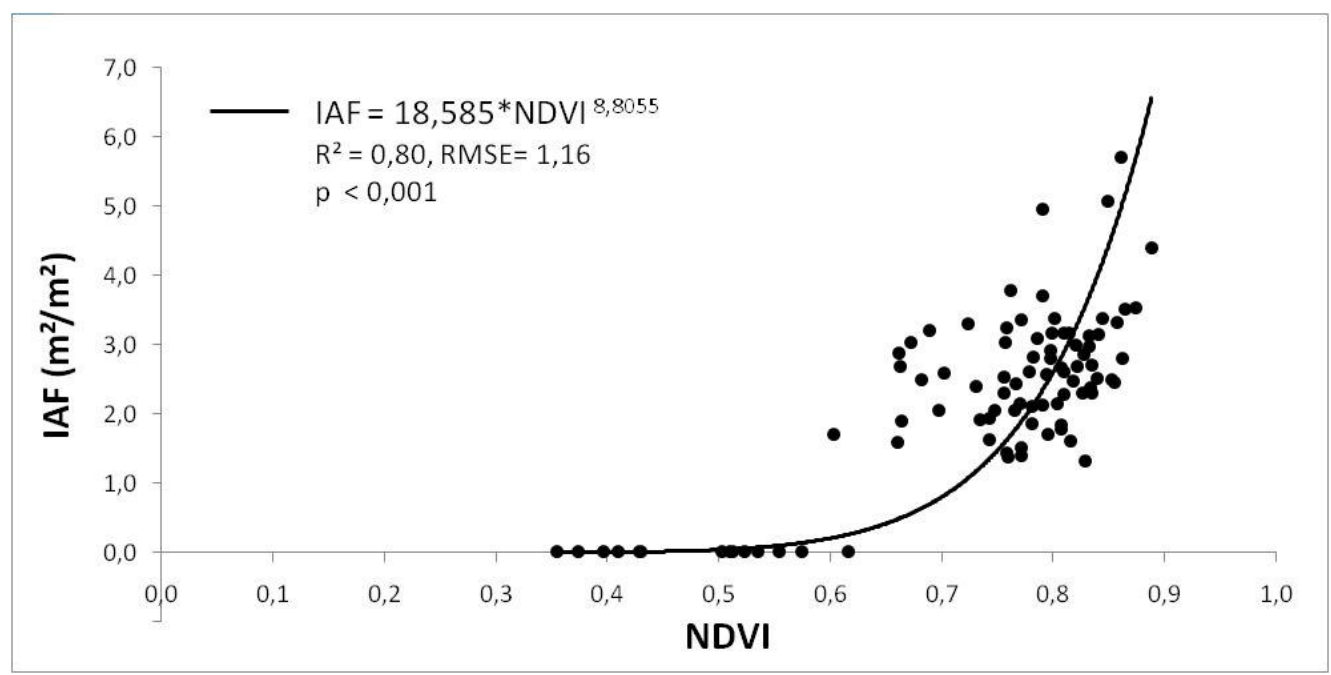

Figura 13. Relação entre IAF medido e NDVI, para todo o conjunto de dados. 
A correlação entre o EVI e o IAF foi realizada através de uma regressão logística, que melhor se adaptou à dispersão dos dados (Figura 14 e 15). 0 ajuste foi realizado encontrando os coeficientes que resultassem em uma otimização buscando a minimização dos erros.

Não foi encontrada uma relação crescente do RMSE e do coeficiente de determinação com o aumento do tamanho dos talhões estudados (Tabela 6), como era esperado. Ao contrário, houve um decréscimo da qualidade dos ajustes (RMSE de $0,43,0,67$ e $0,76 \mathrm{~m}^{2} / \mathrm{m}^{2}$ para os tratamentos 100,150 e 250 , respectivamente).

Porém, assim como com o NDVI, pode ter ocorrido um efeito de incertezas de outras naturezas, não associadas ao tamanho dos talhões. Além disso, existe uma diferença na amplitude dos dados de IAF coletados entre os tratamentos, o que afeta significativamente o ajuste dos valores máximos de IAF da regressão logística. Portanto, para o EVI também foi feito o ajuste da regressão para todos os pontos coletados.

A regressão ajustada aos dados dos três tratamentos juntos obteve uma significância satisfatória $\left(R^{2}=0,90, R M S E=0,81 \mathrm{~m}^{2} / \mathrm{m}^{2}\right.$ e $p$-valor $\left.<0,001\right)$, levando-se em conta a relativa baixa resolução espacial do MODIS, a alta incidência de nuvens na região e a ocorrência de incertezas de diversas naturezas. 


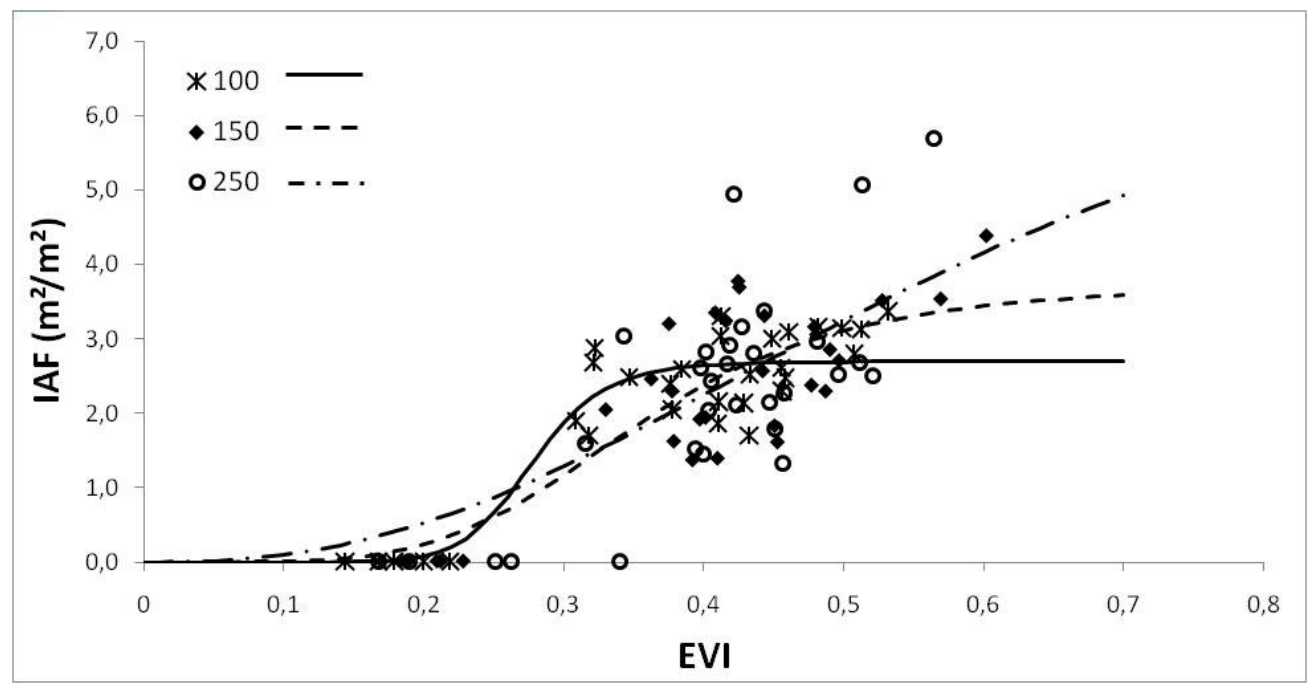

Figura 14. Relação entre IAF medido e EVI, para os três tratamentos testados.

Tabela 6. Equações ajustadas para a relação entre IAF e EVI , coeficiente de determinação $\left(R^{2}\right)$, erro médio quadrático (RMSE) e valor-p para os tratamentos analisados.

\begin{tabular}{ccccc}
\hline Tratamento & Equação ajustada & $\mathbf{R}^{\mathbf{2}}$ & RMSE & Valor-p \\
\hline 100 & $\mathrm{IAF}=2,7 \frac{-2,7}{1+\left(\frac{E V I}{0,28}\right)^{10,72}}$ & 0,81 & 0,43 & $<0,001$ \\
150 & $\mathrm{IAF}=3,74 \frac{-3,74}{1+\left(\frac{E V I}{0,35}\right)^{4,69}}$ & 0,62 & 0,67 & $<0,001$ \\
\hline 250 & $\mathrm{IAF}=17,28 \frac{-17,28}{1+\left(\frac{E V I}{0,83}\right)^{2,69}}$ & 0,55 & 0,76 & $<0,001$ \\
\hline
\end{tabular}

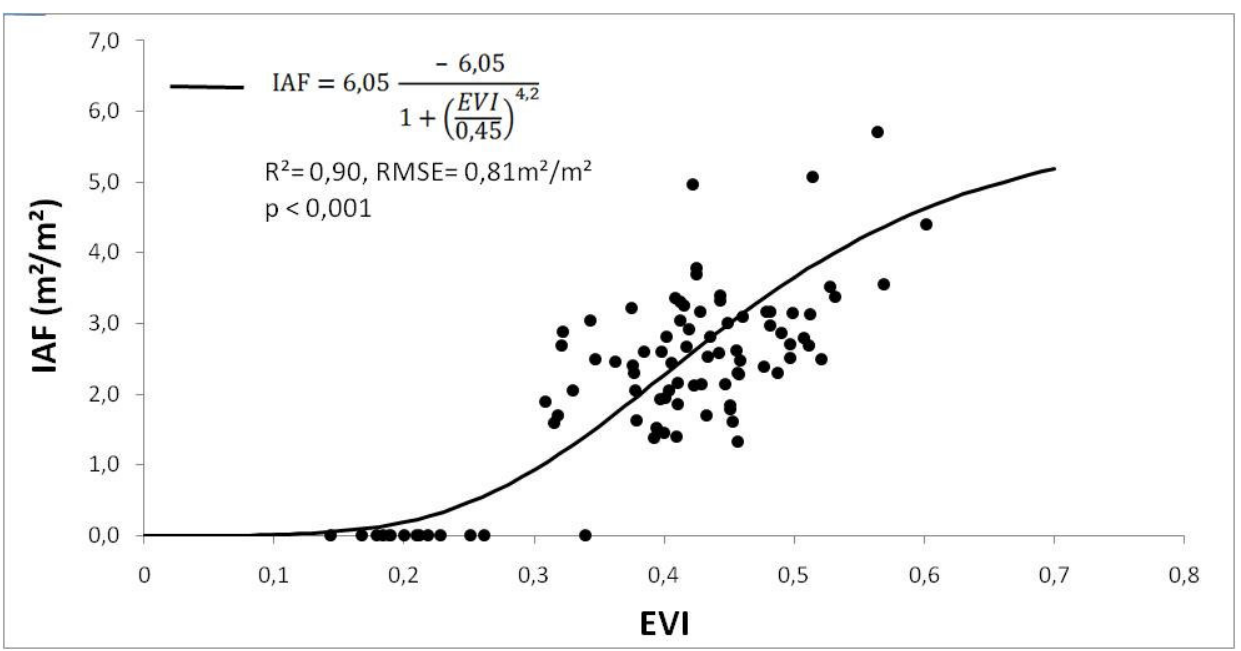

Figura 15. Relação entre IAF medido e EVI, para todo o conjunto de dados. 
A vantagem do uso do EVI em relação ao NDVI é que o EVI foi otimizado para melhorar as leituras em vegetação, trazendo maior sensibilidade para regiões com maior biomassa vegetal, assim como a dissociação dos efeitos de fundo do dossel e uma redução nas influências atmosféricas (HUETE et al., 2002). Esse fato pode explicar a melhor correlação, quando comparados os ajustes dos dados entre todos os tratamentos, do EVI em relação ao NDVI.

Outra vantagem do EVI sobre o NDVI, para este estudo, é que o NDVI foi desenvolvido para ter maior sensibilidade aos índices de clorofila das plantas, enquanto que o EVI é mais responsivo às variações de dossel, incluindo índice de área foliar, estrutura de dossel, tipo de cultura, entre outros (GAO et al., 2000).

Para o prosseguimento do estudo, decidiu-se trabalhar com o EVI, pelas razões citadas acima.

\subsection{Verificação da eficácia do modelo}

A verificação da eficácia do modelo de IAF em função do índice de vegetação EVI, é apresentada nas Figuras 16 e 17. Observou-se uma correlação significativa entre os valores de IAF mensurados em campo e os estimados pela regressão $\left(R^{2}=0,737\right.$ e RMSE $\left.=0,67 \mathrm{~m}^{2} / \mathrm{m}^{2}\right)$, sendo que há uma pequena tendência de subestimação dos valores de IAF pelo modelo. A dispersão dos erros (Figura 17) mostra que a maioria dos desvios estão entre $+/-1,0 \mathrm{~m}^{2} / \mathrm{m}^{2}$, e possuem uma tendência para apresentar maior desvio nos valores intermediários.

O maior acerto do modelo para os valores extremos (mínimos e máximos) é extremamente favorável, pois uma das principais aplicações desse modelo é a avaliação do tempo de fechamento do dossel após o plantio, ou seja, o tempo que o talhão leva para sair de um IAF perto de zero até valores de 4 a $5 \mathrm{~m}^{2} / \mathrm{m}^{2}$. Esse tipo de indicador reflete a qualidade do plantio e produtividade da floresta. 


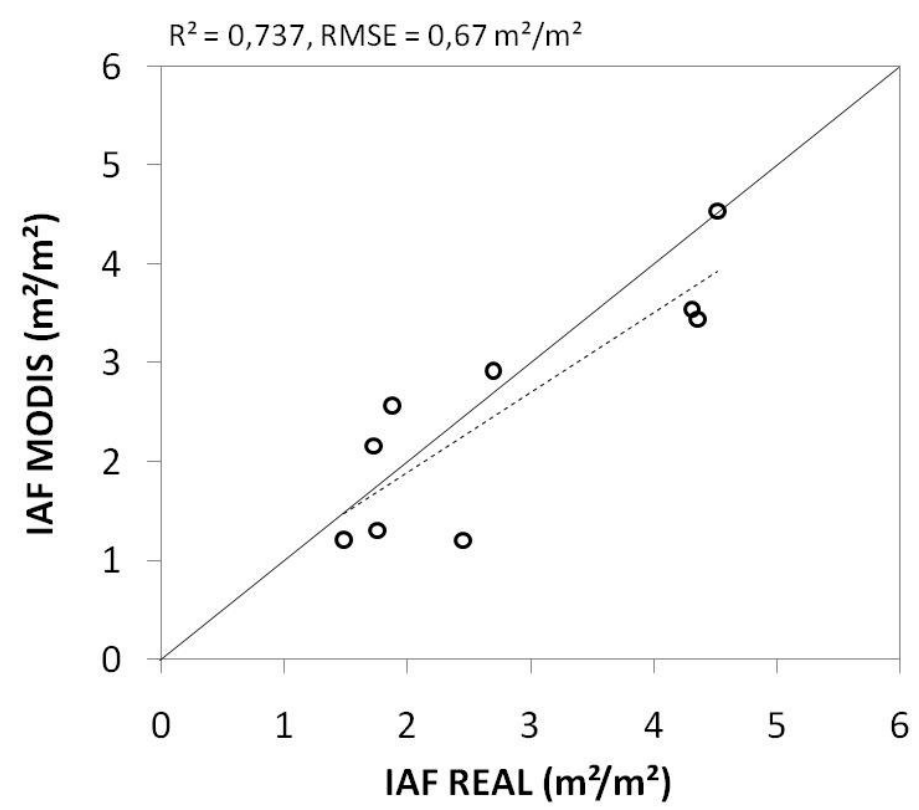

Figura 16. Relação entre IAF real e o estimado pelo MODIS, para os dados de verificação.

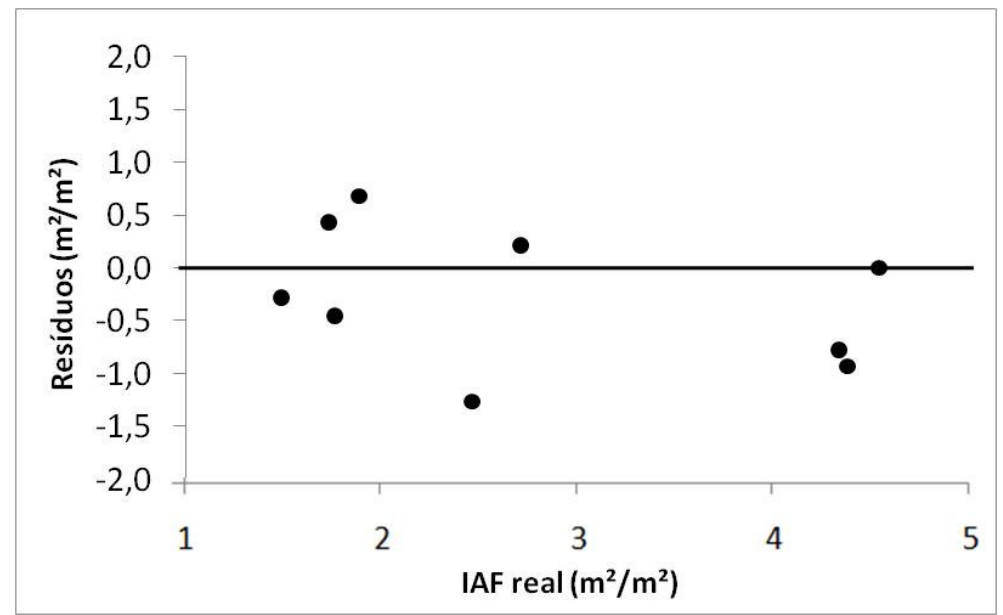

Figura 17. Dispersão dos resíduos em função do IAF real medido em campo.

Na Figura 18 e na Tabela 7, é possível observar os pontos de verificação coletados em 2007 em relação à série temporal de IAF estimada pelo MODIS. Apesar dos bons índices de correlação obtidos pelo modelo, é importante que essa verificação seja realizada em mais pontos na série temporal, para que sejam contempladas situações climáticas diferentes. 
Em algumas situações na Figura 18, é observado um efeito de sazonalidade no IAF das florestas, com a aumento e queda dos valores de IAF dentro de um mesmo ano. Isso pode estar associado ao comportamento natural do IAF nas florestas em resposta às diferenças climáticas dentro de um mesmo ano (como radiação disponível, água no solo, entre outros), ou mesmo diferenças nas leituras do satélite, como ângulo solar e iluminação. Para melhor entender essas variações sazonais, sugere-se realizar um monitoramento com duas ou mais mensurações de IAF em campo, por ano, para cada uma das áreas avaliadas. Também é interessante avaliar anos diferentes, para que possam ser consideradas diferentes condições climáticas, atmosféricas e de desenvolvimento da floresta.

A constante alteração de materiais genéticos plantados e as mudanças nos padrões climáticos tornam necessário ainda o monitoramento constante de campo para acompanhar a eficiência do modelo ao longo do tempo.

Tabela 7. Áreas de verificação com coordenadas, idade, IAF real e estimado e datas dos inícios dos ciclos de plantio.

\begin{tabular}{|c|c|c|c|c|c|c|c|}
\hline & Área & Latitude & Longitude & $\begin{array}{l}\text { Idade na } \\
\text { avaliação }\end{array}$ & $\begin{array}{l}\text { IAF } \\
\text { real }\end{array}$ & $\begin{array}{c}\text { IAF } \\
\text { estimado }\end{array}$ & $\begin{array}{c}\text { Datas de início } \\
\text { do ciclo }\end{array}$ \\
\hline \multirow[t]{2}{*}{1} & VCC067-00701 & $15^{\circ} 58^{\prime} 56^{\prime \prime S}$ & $39^{\circ} 30^{\prime} 21^{\prime \prime W}$ & 8,7 & 1,49 & 1,21 & 03/02/1999 \\
\hline & & & & & & & 04/09/2009 \\
\hline 2 & VCC067-00201 & $15^{\circ} 59^{\prime} 33^{\prime \prime S}$ & $39^{\circ} 30^{\prime} 37^{\prime \prime} \mathrm{W}$ & 8,6 & 1,76 & 1,31 & 09/02/1999 \\
\hline \multirow[t]{2}{*}{3} & VCC065-04801 & $16^{\circ} 2^{\prime} 17^{\prime \prime S}$ & $39^{\circ} 26^{\prime} 28^{\prime \prime W}$ & 8,5 & 1,88 & 2,57 & 20/03/1999 \\
\hline & & & & & & & $18 / 03 / 2009$ \\
\hline \multirow[t]{2}{*}{4} & VCC065-05001 & $16^{\circ} 2^{\prime} 57^{\prime \prime S}$ & $39^{\circ} 26^{\prime} 29^{\prime \prime} \mathrm{W}$ & 8,6 & 2,45 & 1,20 & 02/03/1999 \\
\hline & & & & & & & 29/04/2009 \\
\hline \multirow[t]{3}{*}{5} & VCC016-01601 & $16^{\circ} 3^{\prime} 46^{\prime \prime S}$ & $39^{\circ} 13^{\prime} 29^{\prime \prime} \mathrm{W}$ & 4,5 & 1,73 & 2,16 & $14 / 10 / 1994$ \\
\hline & & & & & & & $30 / 03 / 2003$ \\
\hline & & & & & & & 01/03/2010 \\
\hline \multirow[t]{3}{*}{6} & VCC059-01601 & $16^{\circ} 9^{\prime} 11^{\prime \prime S}$ & $39^{\circ} 20^{\prime} 22^{\prime \prime} \mathrm{W}$ & 1,9 & 4,52 & 4,53 & $15 / 09 / 1998$ \\
\hline & & & & & & & $29 / 10 / 2005$ \\
\hline & & & & & & & $16 / 06 / 2011$ \\
\hline \multirow[t]{2}{*}{7} & VCC023-01901 & $16^{\circ} 10^{\prime} 27^{\prime \prime S}$ & $39^{\circ} 24^{\prime} 10^{\prime \prime} \mathrm{W}$ & 1,8 & 4,36 & 3,44 & $27 / 05 / 1995$ \\
\hline & & & & & & & $08 / 12 / 2005$ \\
\hline \multirow[t]{2}{*}{8} & VCC050-00801 & $16^{\circ} 13^{\prime} 14^{\prime \prime S}$ & $39^{\circ} 15^{\prime} 20^{\prime \prime} \mathrm{W}$ & 8,7 & 2,70 & 2,92 & $12 / 01 / 1999$ \\
\hline & & & & & & & $20 / 01 / 2008$ \\
\hline \multirow[t]{2}{*}{9} & VCC051-03101 & $16^{\circ} 41^{\prime 2} 21^{\prime \prime S}$ & $39^{\circ} 24^{\prime} 30^{\prime \prime} \mathrm{W}$ & 2,4 & 4,31 & 3,54 & $15 / 04 / 1998$ \\
\hline & & & & & & & $19 / 05 / 2005$ \\
\hline
\end{tabular}


Através da Figura 18 também é possível observar algumas aplicações práticas da avaliação da dinâmica de IAF em séries temporais. Como citado anteriormente, um aspecto importante em florestas plantadas é o tempo para o fechamento da copa, ou seja, o tempo para a floresta atingir seu IAF máximo. Observa-se que, para a área 4, esse tempo foi de aproximadamente 2 anos (a partir de abril de 2009), enquanto que para a área 9, esse tempo foi de aproximadamente 1,5 anos (a partir de maio de 2005), e para a área 5 foi de 1 ano (a partir de março de 2003).

Outra aplicação prática, é a identificação dos eventos de colheita da floresta, para verificação dos apontamentos de campo. Percebe-se que no caso da área 2, não haviam registros de colheita e início de um novo ciclo desde 1999, porém, observa-se uma queda repentina do IAF no final do ano de 2009, que se mantém constante por dois anos, indicando um evento de colheita ou ocorrência de dano significativo à floresta.

Outro exemplo de aplicação operacional que pode ser realizada é a verificação de efeitos de eventos indesejados causadores de danos, como incêndios, ocorrência de pragas e doenças, secas prolongadas e problemas fisiológicos, avaliando os níveis de queda de IAF e sua taxa de recuperação. 
Áreas
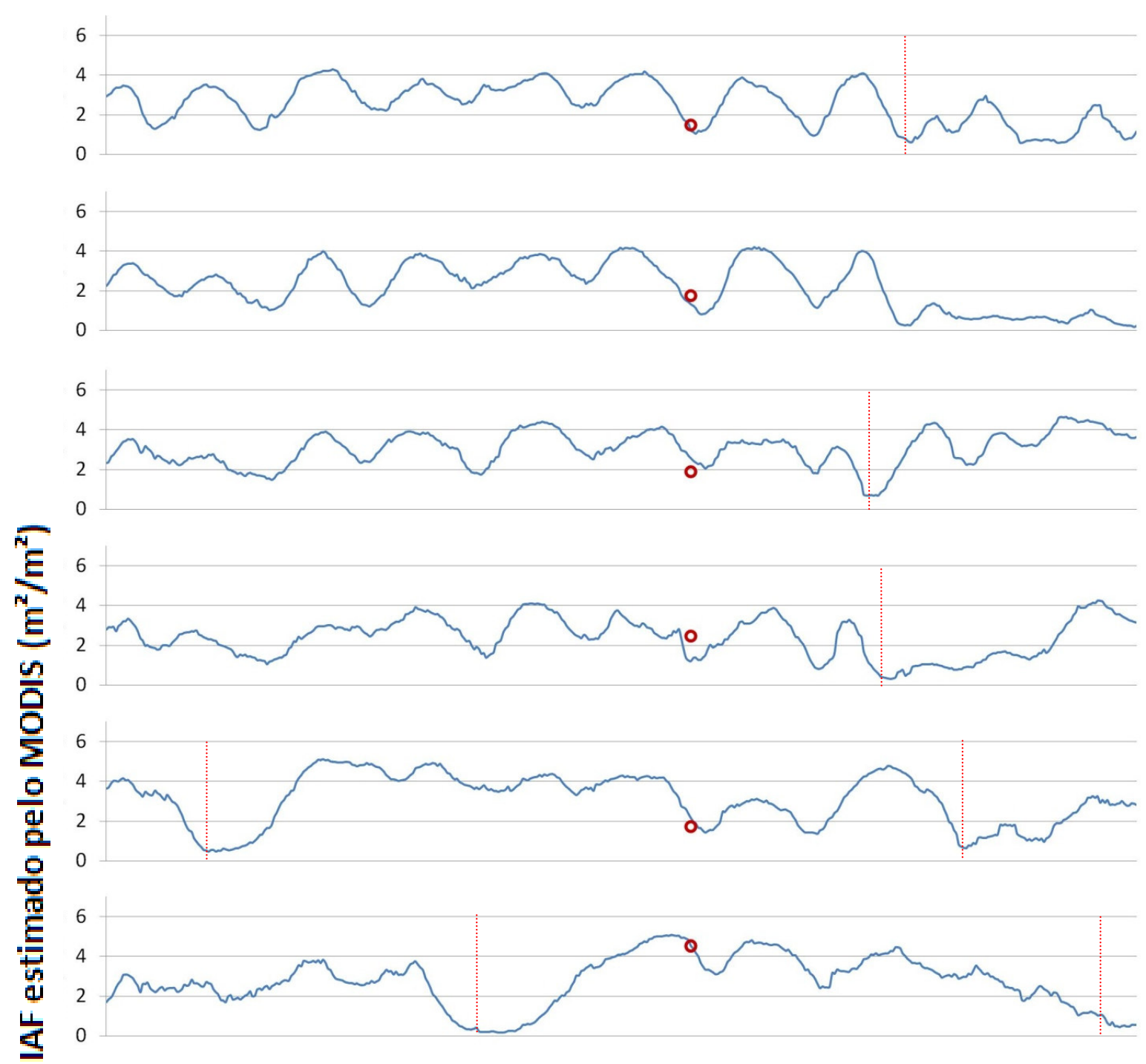

E
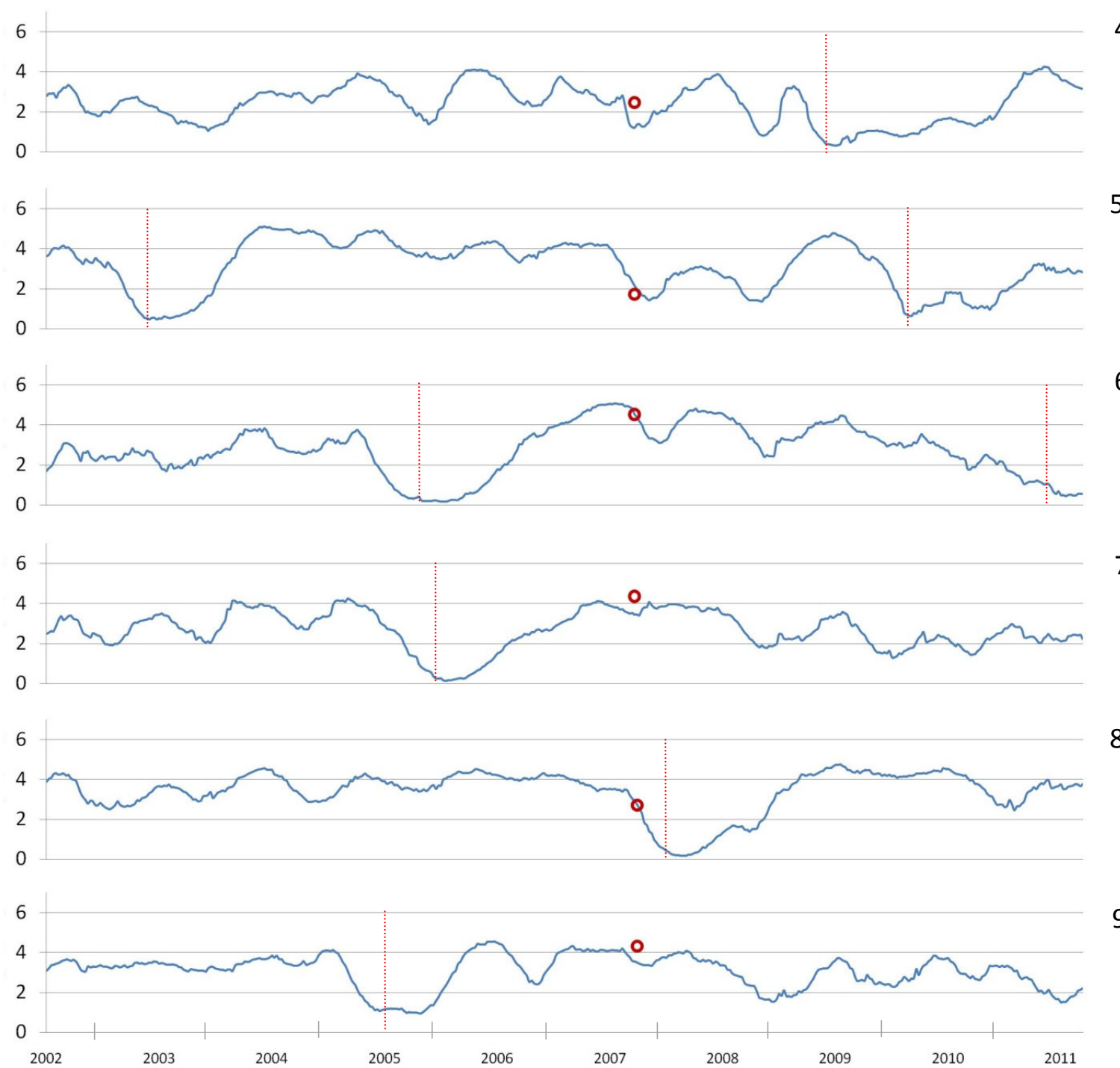

Figura 18. Séries temporais de IAF para as áreas de verificação e valores obtidos em campo (pontos em vermelho). A linha tracejada ( vermelha) indica o corte e início de um novo ciclo da floresta. 


\subsection{Estrutura final da base de dados}

Foi estruturado um banco de dados para armazenamento das informações do estudo para aplicação como ferramenta prática, contendo as informações básicas e processadas, assim como informações auxiliares, como data de plantio e código do local, para associar com outras variáveis de interesse existentes, como tipo de solo, clima, entre outros. A estrutura dos campos do banco de dados é exibida na Tabela 8.

Tabela 8. Estrutura do banco de dados para armazenamento das informações processadas.

\begin{tabular}{|l|l|l|}
\hline Campo & Descrição & Valores \\
\hline Local & Código do talhão/área representada pelo pixel & Texto \\
\hline Data & Data de referência da informação do pixel & Data \\
\hline Idade plantio & Idade do plantio do talhão em meses & $0-\infty$ \\
\hline UTM X & Coordenada x do centróide do pixel & $0-\infty$ \\
\hline UTM Y & Coordenada y do centróide do pixel & $0-\infty$ \\
\hline Azul & Reflectância na banda do azul & $0-10000$ \\
\hline Vermelho & Reflectância na banda do vermelho & $0-10000$ \\
\hline IVP & Reflectância na banda do infravermelho próximo & $0-10000$ \\
\hline EVI original & Cálculo do EVI & $0-1$ \\
\hline IQ & Índice de qualidade do pixel & 0 ou 1 \\
\hline EVI tratado & EVI tratado pela filtragem da série temporal (SG) & $0-1$ \\
\hline IAF calculado & IAF calculado através da equação proposta & $0-10$ \\
\hline
\end{tabular}




\section{CONCLUSÕES}

Através do estudo, foi possível desenvolver uma ferramenta prática para obtenção de séries temporais de IAF de florestas de Eucalyptus no sul da Bahia através de índices de vegetação de imagens do sensor MODIS, concluindo-se que:

- é importante realizar uma filtragem de dados inconsistentes, assim como fazer o pós-processamento da série temporal, para minimizar os efeitos de ruídos na leitura do sensor;

- o tamanho dos talhões avaliados não influenciou na qualidade das estimativas, permitindo que o modelo pudesse ser aplicado para talhões com diversos tamanhos, respeitando que o limite do pixel do MODIS esteja totalmente inserido dentro da área avaliada;

- foi possível estimar o IAF através dos índices de vegetação gerados, sendo que o EVI obteve maior correlação e o menor erro quadrático em relação ao NDVI $\left(R^{2}=0,90, R M S E=0,81 \mathrm{~m}^{2} / \mathrm{m}^{2}\right.$ e $\mathrm{p}$-valor $<0,001$, para o $\left.\mathrm{EVI}\right)$. A verificação da eficácia do modelo confirmou os resultados obtidos $\left(R^{2}=0,737\right.$ e $\left.R M S E=0,67 \mathrm{~m}^{2} / \mathrm{m}^{2}\right)$;

- sugere-se a continuidade do monitoramento de IAF em campo, para que essa verificação possa ser realizada em diferentes condições climáticas (por exemplo, inverno e verão) e diferentes materiais genéticos;

- esse trabalho tem potencial de aplicabilidade em estudos ecofisiológicos (relação das respostas fisiológicas da planta com o meio físico), através da avaliação da dinâmica do IAF em séries temporais, e também aplicações práticas para áreas operacionais, como verificação de corte e avaliação de danos de diversas naturezas. 


\section{REFERÊNCIAS BIBLIOGRÁFICAS}

ABRAF - Associação Brasileira de Produtores de Florestas Plantadas. Anuário Estatístico da ABRAF: ano base 2010. Brasília-DF, 2011, 130 p.

ARAGÃO, J.R.L.; ARAI, E.; SHIMABUKURO, Y.E. Preparação dos produtos MODIS para aplicações operacionais como o Projeto DETER (Detecção de áreas desflorestadas em tempo quase real). In: SIMPÓSIO BRASILEIRO DE SENSORIAMENTO REMOTO, 14. (SBSR), 2009, Natal. Anais... São José dos Campos: INPE, 2009.

BEADLE, C.L., TURNBULL, C.R.A., Comparative growth rates of Eucalyptus in native forest and in plantation monoculture. In: Calder, I.R., Hall, R.L., Adlard, P.G. (Eds.), Growth and Water Use of Forest Plantations. Wiley, Chichester, 1992, $381 \mathrm{p}$.

CARDOZO, F.S.; MARTINS, F.S.R.V.; PEREIRA, L.O.; SATO, L.Y.; MOURA, Y.M.; PEREIRA, G.; SHIMABUKURO, Y.E. Avaliação de áreas queimadas a partir dos índices espectrais NDVI e NDB. In: SIMPÓSIO BRASILEIRO DE SENSORIAMENTO REMOTO, 15. (SBSR), 2011, Curitiba. Anais.... São José dos Campos: INPE, 2011.

DUNGAN, J.L.; GANAPOL, B.D. Sources of uncertainty in the prediction of LAI/fPAR from MODIS. In: AGU FALL MEETING, 2002, San Francisco. Anais... American Geophysical Union, 2002.

FREITAS, R.M.; SHIMABUKURO, Y.E. Combining wavelets and linear spectral mixture model for MODIS satellite sensor time series analysis. Journal of Computational Interdisciplinary Sciences, v.1, p.33-38, 2008.

FREITAS,R.M.; ARAI, E.; ADAMI, M.; SOUZA, A.F.; SHIMABUKURO, Y.E; RUDORFF, B.F.T.; YUZO, F.; ROSA, R.R. Visualização Instantânea de Séries Temporais EVI2MODIS na América do Sul. In: SIMPÓSIO BRASILEIRO DE SENSORIAMENTO REMOTO, 15. (SBSR), 2011, Curitiba. Anais... São José dos Campos: INPE, 2011. 
GAO, X., HUETE, A. R., NI, W., MIURA, T. Optical-biophysical relationships of vegetation spectra without background contamination. Remote Sensing of Environment, 74, 609-620, 2000.

GIUNTI NETO, C.J. Calibração do uso de fotos hemisféricas, do LAl-2000 e do Ceptômetro para a estimativa do índice de área foliar em plantações florestais de eucalipto. 2007. 58p. Monografia (Trabalho de Conclusão de Curso de Engenharia Florestal) - Escola Superior de Agricultura "Luiz de Queiroz", Universidade de São Paulo, Piraricaba, 2007.

GIUNTI NETO, C.J.; STAPE, J.L.; HAKAMADA, R.E.; SILVA, S.R. Relationship between leaf area index and productivity on Eucalyptus Plantation. In: International Conference on Processes Controlling Productivity in Tropical Plantations, Porto Seguro, 2008. Anais... Piracicaba: IPEF, 2008.

GONÇALVES, E. Geologia econômica e recursos minerais. Ilhéus: CEPLAC/IICA, 1975. 142 p. (Diagnóstico sócio-econômico da região cacaueira, 6)

HUETE, A. R. A soil-adjusted vegetation index (SAVI). Remote Sensing of Environment, 25, 295-309, 1988

HUETE, A.R., DIDAN, K.; MIURA, T.; RODRIGUEZ, E.P.; GAO, X.; FERREIRA, L.G. Overview of the radiometric and biophysical performance of the MODIS vegetation indices. Remote Sensing of Environment, 83, p. 195-213, 2002.

JÖNSSON, P., \& EKLUNDH, L. Timesat-A program for analyzing time-series of satellite sensor data. Computers and Geosciences, 30(8), 833-845, 2004.

JUSTICE, C.O., VERMOTE, E., TOWNSHEND, J. R. G., DEFRIES, R., ROY, D. P., HALL, D. K., SALOMONSON, V. V., PRIVETTE, J. L., et al. The Moderate Resolution Imaging Spectroradiometer (MODIS): land remote sensing for global change research. IEEE Transactions on Geoscience and Remote Sensing, 36, p. 1228-1249, 1998.

LANDSBERG, J.. Physiology in forest models: history and the future. Forest Biometry, Modelling and Information Science. 1, 49-63, 2003. 
MARSDEN, C.; le MAIRE, G.; STAPE, J. L.; SEEN, D. L.; ROUPSARD, O.; CABRAL, O.; EPRON, D.; LIMA, A.N.M.; NOUVELLON, Y. Relating MODIS vegetation index time-series with structure, light absorption and stem production of fast-growing Eucalyptus plantations. Forest Ecology and Management, 259, p. 1741-1753, 2010.

ORTIZ, J.A.; VETTORAZZI, C.A.; DO COUTO, H.T.Z.; GONÇALVES, J.L.M. Relações espaciais entre o potencial produtivo de um povoamento de eucalipto e atributos do solo e do relevo. Scientia Florestalis, n. 72, p. 67-79, dez. 2006.

PAIVA, Y.G.; RIBEIRO, A.; ALMEIDA, A.Q.; GLERIANE, J.M.; PEZZOPANE, J.E.M. Estimativa do Índice de Área Foliar (IAF) através de Fotografias Hemisféricas e Índices de Vegetação em plantios clonais de Eucalipto. In: SIMPÓSIO BRASILEIRO DE SENSORIAMENTO REMOTO, 14. (SBSR), 2009, Natal. Anais.... São José dos Campos: INPE, 2009.

PONTES, P.P.B.; ROCHA, J.V.; LAMPARELLI, R.A.C. Análise temporal de índices de vegetação como subsídio à previsão de safras de cana-de açúcar. In: SIMPÓSIO BRASILEIRO DE SENSORIAMENTO REMOTO, 12. (SBSR), 2005, Goiânia. Anais... São José dos Campos: INPE, 2005.

RIZZI, R.; RUDORFF, B.F.T. Imagens do sensor MODIS associadas a um modelo agronômico para estimar a produtividade de soja. Pesquisa Agropecuária Brasileira, v.42, p.73-80, 2007.

RUDORFF, B. F. T.; SHIMABUKURO, Y. E.; CEBALLOS, J. C., (Eds.). O sensor MODIS e suas aplicações ambientais no Brasil. São José dos Campos-SP: Editora Parêntese, 2007. 423 p.

SANO, E..E; ROSA, R.;BRITO,J.L.S; FERREIRA, L.G. Mapeamento semidetalhado do uso da terra no bioma Cerrado. Pesquisa Agropecuária Brasileira, v.43, n.1, p153156, 2008.

SAVITZKY, A., \& GOLAY, M. J. E. Smoothing and differentiation of data by simplified least squares procedures. Analytical Chemistry, 36(8), 1627-1639, 1964. 
STAPE, J.L., RYAN, M., BINKLEY, D. Testing the utility of the 3-PG model for growth of Eucalyptus grandis _ urophylla with natural and manipulated supplies of water and nutrients. Forest Ecology and Management. 193, 219-234, 2004.

STAPE, J.L.; BINKLEY, D.; RYAN, M.; ALVES, J.M.; TAKAHASHI, E.N.; SILVA, C.; FONSECA, S.; LOOS, R.; SILVA, S.R.; HAKAMADA, R.E.; LIMA, A.; GAVA, L.G.; LEITE, F.P.; ANDRADE, H.; BRANCO, G. Environmental regulations of the productivity of Eucalyptus Plantations in tropical areas. In: International Conference on Processes Controlling Productivity in Tropical Plantations, 2008. Anais. IUFRO Canopy Processes Working Group, 2008. p.10.

VETTORAZZI, C.A.; FERRAZ, S.F.B. Silvicultura de precisão: uma nova perspectiva para o gerenciamento de atividades florestais. In: BOREM, A.; GIUDICE, M.P.; QUEIRÓZ, D.M. de; et al. (Ed.). Agricultura de Precisão. Viçosa: os autores, 2000. p.65-75.

XAVIER, A. C.; SOARES, J. V.; ALMEIDA, A. C. Variação do índice de área foliar em clones de eucalipto ao longo do seu ciclo de crescimento. Revista Árvore, v. 26, n. 4 , p. 421- 427, 2002.

XAVIER, A. C.; SOARES, J. V.; ALMEIDA, A. C.; FREITAS, C. C. Estimativa de IAF de plantações de eucaliptos a partir de dados TM/LANDSAT. In: SIMPÓSIO BRASILEIRO DE SENSORIAMENTO REMOTO, 9. (SBSR), 1998, Santos. Anais... São José dos Campos: INPE, 1998.

XAVIER, A. C.; VETTORAZZI, C. A. Mapping leaf area index through spectral vegetation indices in a subtropcal watershed. International Journal of Remote Sensing, $v$. 25, n. 9, p. 1661-1672, 2004.

YUAN, H., DAI, Y.; XIAO, Z.; JI, D.; SHANGGUAN, W. Reprocessing the MODIS Leaf Area Index products for land surface and climate modelling. Remote Sensing of Environment, 115, p. 1171-1187, 2011. 